\title{
Silence of the Innocents: Illegal Immigrants' Underreporting of Crime and their Victimization*
}

\author{
Stefano Comino’ Giovanni Mastrobuoni ${ }^{\ddagger}$ and Antonio Nicolò ${ }^{\S}$
}

October 18, 2016

\begin{abstract}
We analyze the consequences of illegally residing in a country on the likelihood of reporting a crime to the police and, as a consequence, on the likelihood to become victims of a crime. We use an immigration amnesty to address two issues when dealing with the legal status of immigrants: it is both endogenous as well as mostly unobserved in surveys. Right after the 1986 US Immigration Reform and Control Act, which disproportionately legalized individuals of Hispanic origin, crime victims of Hispanic origin in cities with a large proportion of illegal Hispanics become considerably more likely to report a crime. NonHispanics show no changes. Difference-in-differences estimates that adjust for the misclassification of legal status imply that the reporting rate of undocumented immigrants is close to 11 percent. Gaining legal status the reporting rate triples, approaching the reporting rate of non-Hispanics. We also find some evidence that following the amnesty Hispanics living in metropolitan areas with a large share of illegal migrants experience a reduction in victimization. This is coherent with a simple behavioral model of crime that guides our empirical strategies, where amnesties increase the reporting rate of legalized immigrants, which, in turn, modify the victimization of natives and migrants.
\end{abstract}

Keywords: immigration, amnesty, crime reporting, victimization survey. JEL classification codes: J15, K37, K42, R23.

*Authors wish to thank Nancy Chau for her valuable comments on an earlier version of the paper. We would also like to thank seminar participants at universities and workshops, in particular Shanker Satyanath for their helpful comments.

${ }^{\dagger}$ Dipartimento di Scienze Economiche e Statistiche, Università di Udine, Udine (Italy), stefano.comino@uniud.it.

${ }^{\ddagger}$ Giovanni Mastrobuoni Department of Economics University of Essex and Collegio Carlo Alberto, Wivenhoe Park CO43SQ, Colchester UK, gmastrob@essex.ac.uk.

$\S$ University of Padua and University of Manchester - Economics, School of Social Sciences, M13 9PL, Manchester, UK, antonio.nicolo@manchester.ac.uk. 


\section{Introduction}

In 2014 the estimated number of unauthorized immigrants living in the United States reached 11.3 million (representing 3.5 percent of the entire population), up from about 3.5 million in 1990 (Krogstad and Passel, 2014, Warren and Warren, 2013).

One of the most controversial issues is how to deal with this high number of undocumented immigrants, $]^{1}$ with the main policy option being immigration amnesties. Yet, amnesties polarize the electorate. ${ }^{2}$ Public opinion polls show that citizens tend to fear that illegal immigration might not just bring lost jobs and rising welfare costs but also high rates of crime, even if there is no evidence that immigration overall increases crime or incarceration rates (Butcher and Piehl, 1998, Piehl, 2007) or that it severely worsens labor market outcomes of natives (Borjas, 1994, Card, 1990).

Because of such anti-immigration sentiments, a comprehensive immigration reform has eluded the US Congress, and a perfectly divided US Supreme Court has recently blocked President Obama's Immigration Plan that would have shielded up to half of the undocumented immigrant population from deportation, allowing them to work in the US. European institutions, subject to similar political pressure, cannot agree on a common immigration policy. Anti-immigration sentiments have fueled the BREXIT vote in the UK referendum, and more anti-immigration acts may follow in other European countries.

A thorough evaluation of the various consequences of unauthorized migration represents the most likely solution to such gridlock. There is growing evidence on the positive consequences of immigration amnesties. Economists have shown that

\footnotetext{
${ }^{1}$ Throughout the study we use the words "unauthorized", "undocumented," and "illegal" interchangeably to define immigrants who are illegally residing in the country.

${ }^{2}$ See for instance http://www.pollingreport.com/immigration.htm.
} 
amnesties allow undocumented immigrants to access segments of the labor market granting enhanced employment protection, better working conditions, higher salaries, and the possibility to benefit from better health-care (Kossoudji and Cobb-Clark. 2002, Lozano and Sorensen, 2011). And, as recently pointed out by the Washington Post (Badger, November 26, 2014), acquiring legal status might influence many more outcomes. Immigrants who benefit from an amnesty might invest more in education, in community institutions, as well as in political participation. They may become more likely to learn English, and their children might become more likely to go to college, or to experience upward mobility.

A standard opportunity cost argument, which has also recently been supported by empirical evidence (Baker, 2015, Freedman et al., 2013, Mastrobuoni and Pinotti 2015), implies that, ceteris paribus, documented immigrants have a lower propensity to be involved in criminal activities than undocumented ones. As a result, immigration amnesties should reduce immigrants' participation in crime.

This study contributes to this debate providing evidence on an important negative consequence of illegally residing in the country which is directly borne by the undocumented immigrants: the inability to protect their property and their human right to security. We show that out of fear of deportation undocumented immigrants drastically lower their propensity to report a crime to the police, generating an essentially unenforced space of action for ruthless criminals.

Amnesties might thus not only improve the labor market opportunities of immigrants, thus lowering their criminal propensity, they might also increase reporting rates and thus alter the expected cost of criminal behavior for immigrants and nonimmigrants alike, increasing deterrence.

The evidence on the reporting behavior of undocumented immigrants is still scarce, 
as it either relies on correlational studies that do not measure legal status or on studies that do measure legal status but only for small convenience samples. In search for such evidence we use the National Crime Victimization Survey around the 1986 US immigration amnesty (the Immigration Reform and Control Act, IRCA) to deal with the endogeneity of legal status as well as with its measurement issue.

We show not only that undocumented immigrants are considerably less likely to report a crime to the police, but also that amnesties dramatically alter this situation. We develop a simple empirical strategy to circumvent the main issue when dealing with illegal migrants: in most household surveys legal status is unobservable. ${ }^{3}$ For example, when addressing the question about legal status and reporting behavior, the US National Crime Victimization Survey does not collect information on the legal status of respondents. Yet, if there is a good proxy for the legal status, with known probabilities of misclassification, there are simple econometric techniques to adjust the biased estimates that rely on the proxy (see Aigner, 1973). We adapt this strategy to a difference-in-differences setup, around the IRCA, which granted legal status to about 2.7 million undocumented immigrants (out of 3 million who applied). Since most immigrants who applied for the amnesty were from Central American countries, mainly Mexico, we use Hispanic origin as a proxy for legal status. The 1980 and 1990 Census have information on citizenship (including legal status), Hispanic origin, and immigration year of respondents, which we use to derive the probabilities of misclassification.

Using this "adjusted proxy method" we show that amnesties change the immigrants' incentives to report a crime. Following the IRCA amnesty, as the risk of deportation ceased to exist for IRCA applicants, the reporting rates of eligible un-

\footnotetext{
${ }^{3}$ An important exception is the US Census, a feature that we are going to exploit.
} 
documented immigrants went from 11 percent to 31 percent, approaching the 40 percent reporting rates of non-Hispanics (almost all of which are legal residents).

Since police investigations are unlikely to start without a formal report of the offence, amnesties are likely to increase conviction rate of criminals whose victim is a newly legalized individual, therefore changing the relative benefits of victimizing immigrants versus natives. Whenever ethnicity or other observable characteristics signal the legal status of immigrants, criminals may choose their targets based on such signals. We develop a model of crime where the comparative statics highlight the identification strategy for this amnesty-induced displacement of victimization. Society is composed of two ethnic groups, a native ethnic group and an immigrant ethnic group. Natives and immigrants (both the documented and the undocumented ones) choose whether or not to become criminals, and, in the latter case, against which ethnic group to commit crimes. Criminals trade-off the higher expected booty they can collect targeting more affluent native citizens with the lower probability of being convicted when targeting poorer immigrants. The model predicts amnesties to reduce the victimization of immigrants, and more so in places where a large fraction of immigrants become legalized, delivering a clear difference-in-differences strategy.

We find evidence that following the 1986 IRCA amnesty Hispanics living in metropolitan statistical areas with a large fraction of undocumented immigrants were less likely to become victims of crime. This implies not only that undocumented immigrants are unable to protect some of their fundamental human rights, but also that the absence of this fundamental human right makes them even more vulnerable. It also means that the deterrent effect of law enforcement might be severely damped by the mere existence of such victims.

This paper is related to the literature on the social and economic effects of immi- 
gration, immigration restrictions, and amnesties. Generating sudden changes to the legal status of immigrants, amnesties help better understand the various consequences of residing illegally in a country. Focussing on the 1986 IRCA, which legalized mostly immigrants of Hispanic origin, a few studies have shown that the reform increased job mobility and earnings amongst Hispanic immigrants (see Kossoudji and Cobb-Clark (2002), Lozano and Sorensen (2011), and Barcellos (2010)), while others have found that it reduced crime rates (see Baker (2015) and Freedman et al. (2013)). This paper also exploits the IRCA, in particular its disproportionate impact on immigrants of Hispanic origin.

There is also evidence from other countries showing that granting legal status changes the criminal involvement of immigrants. Mastrobuoni and Pinotti (2015) exploit exogenous variation in legal status following the January 2007 European Union enlargement, while Pinotti (2014) employs Italian data on legalization lotteries..$^{4}$ Both studies find similarly sized large negative legalization effects on the criminal behavior of immigrants. $5^{5}$

A few convenience sample studies document the low propensity of undocumented immigrants to report crimes to the police. Based on interviews in Memphis, Tennessee, Bucher et al. (2010) find that these individuals experience a high rate of victimization and yet are reluctant to report crimes to the police, mainly because of the perceived risk of deportation.

That fear of deportation may induce underreporting amongst Latino immigrants' has also been mentioned in a study about immigrants in Phoenix, Arizona (Menjívar

${ }^{4}$ Pinotti $(2015)$ also provides evidence that stricter enforcement of migration policy reduces the crime rate of undocumented immigrants.

${ }^{5}$ Several studies do not focus on amnesties but rather on the overall effect of immigration on crime. The results are rather mixed, although most recent studies find little evidence that immigration spurs crime (see, among others, Bianchi et al. (2012) and Bell et al. (2013).) 
and Bejarano, 2004), and in one about immigrants in Reno, Nevada (Correia, 2010) ${ }^{6}$. The only study that uses a large and representative sample finds that crime reporting rates are negatively correlated with the relative size of noncitizen and foreign-born individuals living in a metropolitan area (Gutierrez and Kirk, 2015). The authors use the National Crime Victimization Survey, a survey we are also going to draw on for our empirical analysis.

In spirit this study is also closely related to recent research on the determinants of crime reporting of women and victimization against them. Miller and Segal (2014) use the NCVS to show that the integration of women in US police departments increased the reporting behavior of women who were victims of violent crimes, especially domestic violence. Consistent with our finding, they find that the increased reporting behavior leads to subsequent reductions in crime.

That higher reporting rates might reduce the incentives to commit a crime has been discussed in more general terms in some theoretical studies (Garoupa, 2003) as well as in some empirical ones (Goldberg and Nold, 1980, Goudriaan et al., 2006).

The paper is organized as follows. Section 2 sketches a simple model of crime and reporting behavior (all proofs are in the appendix). Results from the model guide the empirical strategy developed in Sections 3 and 4 . Section 5 concludes.

\section{The model}

We consider a society composed of two ethnic groups: natives, with mass $M>0$, and immigrants, with mass 1; immigrants are either legal citizens (mass $1-\gamma$ ) or undocumented (mass $0<\gamma<1$ ). We use the term immigrants loosely to indicate

\footnotetext{
${ }^{6}$ See also Barrick $(2014)$
} 
minorities that contain a group of undocumented immigrants. Later in our empirical section we focus on Hispanic individuals and call them immigrants even if some of them might have been born in the United States. Individuals differ in terms of their wealth: all immigrants are poor, while natives can be rich (mass $M-\phi$ ) or poor (mass $\phi)$. While this is a simplifying assumption, in our case income differences between Hispanics and Non-Hispanics are shown to be large in the National Crime and Victimization Survey (see Figure 2). Household incomes are only available in broad intervals, but relative income differences between the two groups are at least equal to $1 / 4$, and don't seem to depend on whether individuals have been victimized.

Each individual chooses whether to be honest or to commit crimes. Criminals then choose which ethnic group to target, subject to some error, as we specify later. Finally, honest individuals who are victimized decide whether to report the crime to the police.

Each individual is identified by a triple $(t, j, k)$, where $t \in\{r, p\}$ denotes his wealth, rich $(r)$ or poor $(p), j \in\{n, i\}$ his ethnicity, native $(n)$ or immigrant $(i)$, and finally $k \in\{l, a\}$ his legal status, either legal citizen $(l)$, or undocumented immigrant, for brevity, alien $(a)$.

The utility of an individual of type $(t, j, k)$ who chooses to be honest is:

$$
u_{t, j, k}^{h o n}=f\left(w_{t}, \rho_{t, k}\right)-\tau\left(X_{j}, X_{-j}\right),
$$

where $w_{t}$ is his wealth (with $w_{r}>w_{p}$ ) and $\rho_{t, k}$ is the propensity to report a crime, which, as we show below, depends on both his wealth (whether he is rich or poor, $t \in\{r, p\}$ ) and his legal status (whether he is a legal citizen or an alien, $k \in\{l, a\}$ ). We assume that the wellbeing of honest individuals is increasing in wealth and in 
the reporting rate, $\rho_{t, k}$, as reporting implies an ability to protect the property rights: $f\left(w_{t}, \rho_{t, k}\right)$ is differentiable with $\partial f\left(w_{t}, \rho_{t, k}\right) / \partial w_{t}>0$ and $\partial f\left(w_{t}, \rho_{t, k}\right) / \partial \rho_{t, k}>0$. The function $\tau\left(X_{j}, X_{-j}\right)$ measures the disutility from victimization that an individual of ethnicity $j$ suffers, which depends on the number of criminals trying to target his own ethnicity, $X_{j}$, and, because of the targeting error, on the number of those trying to target the other one, $X_{-j} ; \tau\left(X_{j}, X_{-j}\right)$ is a differentiable function with $\partial \tau\left(X_{j}, X_{-j}\right) / \partial X_{j} \geq \partial \tau\left(X_{j}, X_{-j}\right) / \partial X_{-j}>0$.

Criminals do not know the individual characteristics (wealth and reporting rate) of their victims, but observe signals about their legal status. In the US, where most undocumented immigrants are of Hispanic origin, ethnicity would be such a signal. Hence, we assume that criminals choose which ethnic group to target, natives or immigrants, based on their expected wealth and on their expected reporting behavior.

In particular, committing a crime against an individual belonging to the ethnic group $j \in\{n, i\}$, yields $\theta \pi\left(\bar{w}_{j}\right)-C\left(\bar{\rho}_{j}\right)$. The expected booty, $\pi\left(\bar{w}_{j}\right)$, is an increasing function of $\bar{w}_{j}$, the average wealth of the honest individuals belonging to ethnic group $j$; given the fraction of rich and poor individuals in each ethnic group, it follows that $\bar{w}_{n}=(\phi / M) w_{p}+((M-\phi) / M) w_{r}$ and $\bar{w}_{i}=w_{p}$. The parameter $\theta \in[0,1]$ measures the individual's criminal ability, i.e. his ability to appropriate the value of the booty. $C\left(\bar{\rho}_{j}\right)$ is the expected punishment which is assumed to be an increasing and concave function of $\bar{\rho}_{j}$, the reporting rate characterizing ethnic group $j$; recalling that the reporting rate depends on wealth and legal status, it follows that $\bar{\rho}_{n}=$ $(\phi / M) \rho_{p, l}+((M-\phi) / M) \rho_{r, l}$ and $\bar{\rho}_{i}=(1-\gamma) \rho_{p, l}+\gamma \rho_{p, a}$. Finally, we assume that with some positive probability $(1-\xi)<1 / 2$ a criminal who targets group $j$ commits a crime against an individual of group $-j .7$

\footnotetext{
${ }^{7}$ This might occur because of several reasons. For instance, the criminal might mistakenly believe
} 
Summarizing, the expected utility of a native with criminal ability $\theta$ who chooses to become a criminal and to target ethnic group $j \in\{n, i\}$ is:

$$
u_{n, j}^{c r}(\theta)=\theta \Pi\left(\bar{w}_{j}, \bar{w}_{-j}\right)-\xi C\left(\bar{\rho}_{j}\right)-(1-\xi) C\left(\bar{\rho}_{-j}\right)-\tau\left(X_{n}, X_{i}\right)
$$

where $\Pi\left(\bar{w}_{j}, \bar{w}_{-j}\right)=\xi \pi\left(\bar{w}_{j}\right)+(1-\xi) \pi\left(\bar{w}_{-j}\right)$.

The expected utility of a criminal immigrant with ability $\theta$ who targets ethnic group $j \in\{n, i\}$ is the same, except for the last term that now becomes $\tau\left(X_{i}, X_{n}\right)$.

\subsection{The reporting decision}

We assume that the monetary loss that a victim of a crime suffers is not deterministic; for instance, it may depend on the amount of money that the victim is carrying. More specifically, a honest citizen whose wealth is $w_{t}$ suffers a loss $\alpha w_{t} \in\left[0, w_{t}\right]$ when victimized; $\alpha$ is the realization of a random variable distributed according to $F(\alpha)$, with support $[0,1]$. We assume that the victim reports the crime to the police when the monetary loss is larger than the cost of reporting; formally, this occurs when:

$$
\alpha w_{t} \geq T+g_{k} D, \text { or } \alpha \geq \frac{T+g_{k} D}{w_{t}} \equiv \bar{\alpha}_{t, k}
$$

where $T$ is a fixed cost of reporting crime, $g_{k}$ is the probability of deportation which is zero for legal citizens and positive for undocumented immigrants (evidence is provided in the empirical section) - and $D$ is the associated cost. Notice that the threshold $\bar{\alpha}_{t, k}$ becomes smaller with the level of wealth, $w_{t}$, while it becomes larger with the probability, $g_{k}$, and the cost of deportation, $D$; hence $\bar{\alpha}_{p, a}>\bar{\alpha}_{p, l}>\bar{\alpha}_{r, l}$.

that the victim belongs to group $j$ while she actually belongs to group $-j$; alternatively, a criminal acting in the neighborhoods where most of his target citizens live might end up committing a crime against individuals of the other group who are spending time or residing in those neighborhoods. 
The probability that a honest individual reports a crime is simply $\rho_{t, k} \equiv 1-F\left(\bar{\alpha}_{t, k}\right)$. Since $\bar{\alpha}_{p, a}>\bar{\alpha}_{p, l}>\bar{\alpha}_{r, l}$, it follows that $\rho_{r, l}>\rho_{p, l}>\rho_{p, a}$ : the propensity to report a crime to the police is largest for rich natives, lowest for undocumented immigrants, and intermediate for legal immigrants and poor natives.

\subsection{Being honest or criminal?}

Individuals are heterogeneous with respect to their ability to commit crimes. Specifically, we assume that $\theta$ is uniformly distributed on the interval $[0,1]$ for all types $(t, j, k)$. Individuals observes their ability before deciding whether to become criminals.

Criminals prefer to target natives whenever: 8

$$
\theta \geq \frac{C\left(\bar{\rho}_{n}\right)-C\left(\bar{\rho}_{i}\right)}{\pi\left(\bar{w}_{n}\right)-\pi\left(\bar{w}_{i}\right)} \equiv \bar{\theta}
$$

The relevant trade-off when deciding the target ethnic group is between a larger expected booty from crime when targeting natives (since $\bar{w}_{n}>\bar{w}_{i}$ ) with a smaller expected punishment when targeting immigrants (since $\bar{\rho}_{i}<\bar{\rho}_{n}$ ). It follows that criminals with higher abilities $(\theta \geq \bar{\theta})$ prefer to target natives rather than immigrants.

The low ability individuals need to decide whether to be honest or target the immigrant group. We assume that $w_{r}$ is large enough so that all rich natives prefer to be honest. Poor natives and legal immigrants have the same wealth as well as the reporting rate, and therefore behave in the same way; they prefer to commit crimes targeting ethnic group $i$ rather than being honest whenever: 9

\footnotetext{
${ }^{8}$ Formally, a native criminal compares $u_{n, n}^{c r}(\theta)$ with $u_{n, i}^{c r}(\theta)$ while an immigrant criminal $u_{i, n}^{c r}(\theta)$ with $u_{i, i}^{c r}(\theta)$.

${ }^{9}$ Formally, a poor native compares $u_{p, n, l}^{\text {hon }}$ with $u_{n, i}^{c r}(\theta)$ while a legal immigrant compares $u_{p, i, l}^{\text {hon }}$ with $u_{i, i}^{c r}(\theta)$.
} 


$$
\theta \geq \frac{f\left(w_{p}, \rho_{p, l}\right)+\xi C\left(\bar{\rho}_{i}\right)+(1-\xi) C\left(\bar{\rho}_{n}\right)}{\Pi\left(\bar{w}_{i}, \bar{w}_{n}\right)} \equiv \hat{\theta}_{p}
$$

The above condition says that a poor native/legal immigrant prefers to commit offences rather than being honest when his/her criminal ability is large enough: $\theta \geq$ $\hat{\theta}_{p}$

Similarly, for undocumented immigrants, committing crimes targeting immigrants is preferred to being honest when:10

$$
\theta \geq \frac{f\left(w_{p}, \rho_{p, a}\right)+\xi C\left(\bar{\rho}_{i}\right)+(1-\xi) C\left(\bar{\rho}_{n}\right)}{\Pi\left(\bar{w}_{i}, \bar{w}_{n}\right)} \equiv \hat{\theta}_{a}
$$

Looking more closely to the thresholds $\hat{\theta}_{p}$ and $\hat{\theta}_{a}$, it follows that undocumented immigrants have a higher propensity to become criminals than poor natives/legal immigrants, $\hat{\theta}_{a}<\hat{\theta}_{p}$. This is due to their lower reporting rate $\left(\rho_{p, a}<\rho_{p, l}\right)$ which implies a reduced ability to protect their property rights when being honest.

Figure 1 provides a graphical representation of the equilibrium choices of undocumented immigrants depending on $\theta$ : individuals with low criminal ability $\left(\theta<\hat{\theta}_{a}\right)$ prefer to be honest, those with intermediate ability $\left(\hat{\theta}_{a} \leq \theta<\bar{\theta}\right)$ become criminals and target immigrants, while individuals with high criminal skills $(\theta \geq \bar{\theta})$ become criminals who target natives ${ }^{11}$ For poor natives/legal immigrants the equilibrium choices and their graphical representation are similar, with threshold $\hat{\theta}_{p}$ in place of $\hat{\theta}_{a}$.

Recalling that $\gamma$ represents the mass of undocumented immigrants while $(1-\gamma+\phi)$ represents the mass of poor natives and legal immigrants, it follows that the number

\footnotetext{
${ }^{10}$ Undocumented immigrants compare $u_{p, i, a}^{h o n}$ with $u_{i, i}^{c r}(\theta)$.

${ }^{11}$ We focus on the most interesting case $\hat{\theta}_{a}<\bar{\theta}$ which implies that both ethnic groups are targeted by criminals.
} 


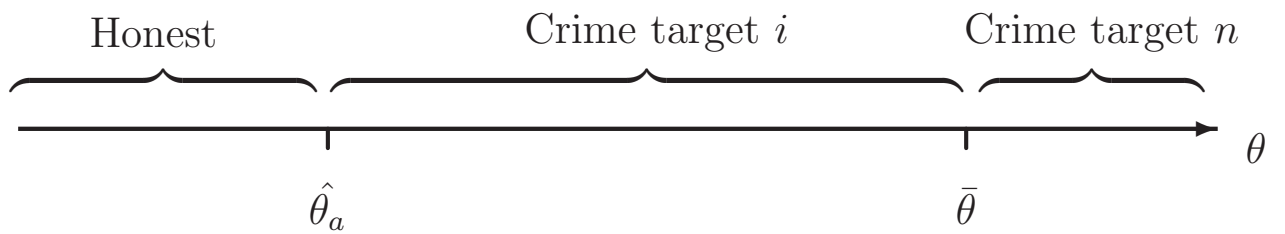

Figure 1: Equilibrium choice of undocumented immigrants

of criminals targeting immigrants and natives is:

$$
X_{i}=\gamma\left(\bar{\theta}-\hat{\theta}_{a}\right)+(1-\gamma+\phi)\left(\bar{\theta}-\hat{\theta}_{p}\right)
$$

and

$$
X_{n}=\gamma(1-\bar{\theta})+(1-\gamma+\phi)(1-\bar{\theta})=(1+\phi)(1-\bar{\theta}) \text {. }
$$

Moreover, since criminals targeting group $j \in\{n, i\}$ commit crimes against members of the other group with probability $(1-\xi)$, the number of criminals to which immigrants and natives are actually "exposed to" is:

$$
\begin{aligned}
& X_{i}^{\mathrm{ex}}=\xi X_{i}+(1-\xi) X_{n}, \\
& X_{n}^{\mathrm{ex}}=\xi X_{n}+(1-\xi) X_{i} .
\end{aligned}
$$

\subsection{The effect of an amnesty}

Next we consider the effects of an amnesty which legalizes a fraction $x \in(0,1]$ of undocumented immigrants. The amnesty eliminates the risk of deportation, increasing their reporting rate from $\rho_{p, a}$ to $\rho_{p, l}$; this, in turn, allows immigrants to better protect 
their property rights. As a consequence, the average reporting rate of immigrants goes up to $\bar{\rho}_{i}(x)=(1-\gamma+\gamma x) \rho_{p, l}+\gamma(1-x) \rho_{p, a}$. Notice that the change in the average reporting rate of immigrants, $\bar{\rho}_{i}(x)-\bar{\rho}_{i}=\gamma x\left(\rho_{p, l}-\rho_{p, a}\right)$, is increasing in $\gamma$, the initial share of undocumented immigrants.

Proposition 1 characterizes the impact of amnesties on the overall level of crime as well as the victimization of each targeted groups.

Proposition 1. Amnesties reduce the overall number of criminals. They also reduce the share of criminals targeting immigrants (increasing the share of criminals targeting natives). These changes increase with $\gamma$, the initial share of undocumented immigrants.

The overall level of crime drops because of two effects. First, the increase in the average reporting rate of immigrants raises the expected cost of punishment, reducing criminals' payoffs ( $\hat{\theta}_{p}$ and $\hat{\theta}_{a}$ increase). In addition, without the risk of deportation, legalized immigrants are better able to protect their property and their reporting rate increases from $\rho_{p, a}$ to $\rho_{p, l}$. This reduces their propensity to become criminals as $\hat{\theta}_{p}$, rather than $\hat{\theta}_{a}$, becomes the relevant threshold. Moreover, amnesties also change the distribution of crime. Because of the higher reporting rate of immigrants, some of those who decide to remain criminals may be better off targeting natives rather than immigrants $(\bar{\theta}$ decreases $)$.

These changes reduce the share of criminals that try to target immigrants. Since the increase in the average reporting rate of immigrants is proportional to $\gamma$, all these changes are larger when the initial share of undocumented immigrants is larger.

The next proposition established how amnesties change the number of crimes, rather than the share of crimes, committed against natives and immigrants: $X_{n}^{e x}$ and $X_{i}^{e x}$. 
Proposition 2. An amnesty reduces the number of crimes committed against immigrants, while depending on the parameter $\xi$ it can either increase or decrease those committed against natives. The reduction in the victimization of immigrants grows with the initial share of undocumented immigrants.

Amnesties change the overall level of crime as well as its distribution across ethnicities. The two effects reinforce each other in the case of the immigrants, causing a reduction in their victimization ( $X_{i}^{e x}$ reduces). By contrast, they work in opposite direction in the case of the natives. When $\xi$ is closer to $1 / 2$, meaning that criminals are more likely to mistakenly target the wrong ethnicity, natives benefit substantially from the reduction in the overall level of crime and native victimization rates decrease. When $\xi$ is closer to one the shift in the criminal target is the dominant effect, and native victimization rates increase (larger $\left.X_{n}^{e x}\right)$.

All these changes are more marked when a larger fraction of immigrants become legalized (larger $\gamma$ ), a comparative status result that we are going to exploit in our difference-in-differences strategy (see Section 4.1.2).

Summarizing, amnesties are predicted to:

- reduce immigrants' fear of deportation, and thus increase their crime reporting;

- reduce the payoff of victimizing immigrants;

- reduce the overall number of criminals; not only because some victims are more likely to report a crime but also because immigrants are now better able to protect their own property, increasing their opportunity cost of becoming a criminal;

- reduce the number of immigrants who are victims of crime. 
All these changes, except the first one, grow with $\gamma$, the initial share of immigrants who are undocumented. Finally, amnesties

- can increase or reduce the number native victims, depending on how often criminals mistakenly target a group (depending on $\xi$ ).

\section{Main Data Sources and Measurement Strategies}

This section describes the main data sources used in the empirical section.

\subsection{Reporting and Victimization data}

The analysis of crime reporting behavior and victimization relies on victimization surveys. We use the National Crime Victimization Survey (NCVS), conducted by the Bureau of Justice Statistics (BJS) since 1973. The survey with sufficient geographic information covers the 40 largest Metropolitan Statistical Areas (MSAs) and can be merged with geographic information on the presence of undocumented immigrants. The survey asks a nationally representative sample of individuals about crime incidents, and whether these have been reported or not to police. Crimes include rapes, assaults, including sexual ones, robberies, purse snatching, burglaries, motor vehicle thefts, and other thefts.

We focus on a symmetric time window-from 1981 to 1994-around 1987 and 88, when the IRCA applications were filed (see the left panel of Fig. 3). Post 1994 years are excluded because of the 1994 Immigration and Nationality Act (which went into effect at the end of 1994) which introduced a temporary amnesty for about half a million undocumented immigrants. Since we are going to compare reporting and victimization rates for Hispanic and non-Hispanic respondents, we exclude race 
categories that are not Hispanic (American Indians, less 1 percent of the sample; Asians, about 4 percent; individuals for whom no race is specified, about 7 percent). The NCVS contains information about the age range of respondents. We focus on adult respondents. The Summary Statistics Table 1 shows that we have an overall sample of about one million respondents, and about 10 percent of which are victims of a crime 12 Of these only 39 percent report the crime to the police. The list of MSAs included in the sample is reported in Table 2.

The victimization survey contains information on whether the victim reported the crime to the police but does not contain information about the immigration status of respondents. To reconstruct such a measure we exploit two additional datasets.

\subsection{IRCA's Legalization Summary Public Use Tape}

In order to measure of the fraction of Hispanic population that was eligible for the amnesty in each MSA we merge the NCVS survey with the administrative records of IRCA applicants. This gives us the exact number of applicants at the MSA level (we are going to see that the majority of applicants came from the largest MSAs). Next, to measure the probabilities of eligibility by age, race, Hispanic origin, and gender we use the 1980 Census.

\subsection{CENSUS data}

In order to be eligible unauthorized immigrants had to be in continuous residence since January 1, 1982 (for a total of 5 years.) Temporary residency lasted 18 months, after which the legalized immigrants became eligible for permanent residency (i.e.,

\footnotetext{
${ }^{12}$ For respondents who report being victimized several times there is one observation for each incident. This allows us to properly characterize the incident and to properly account for multiple victimizations.
} 
green cards). Approximately 1.75 million people applied for legalization through the program and about $94 \%$ of applications were approved for temporary residency. ${ }_{[}^{13}$

The 1980 and 1990 decennial Censuses from the IPUMS allow us to estimate the population of Hispanic and non-Hispanic individuals, by MSA, race, age, and gender. While the IRCA years do not coincide with a Census year, we show that the estimated fractions of eligible individuals are very similar, no matter whether we use the 1980 or the 1990 Census.

\subsection{Measurement Strategies}

We exploit two features about the 1986 IRCA amnesty to circumvent the issue that immigration status and legal status are both unobserved in the victimization surveys. The first is that Hispanics represent the grand majority of applicants and can thus be used as a proxy for illegal migrants. The left panel of Figure 3 shows, based on administrative records about IRCA applicants (see Section 3.2, that between 1987 and 1988 about 1.6 million Hispanics applied for legal status in the Metropolitan Statistical Areas (MSAs) covered by the NCVS. The number of non-Hispanic applicants was almost an order of magnitude smaller. Given that Hispanics made up only about 10 percent of the total population, the likelihood that someone of Hispanic origin was an IRCA applicant is about two orders of magnitude larger than for non-Hispanics (see Table 1). Using Hispanic origin as proxy for legal status is subject to misclassification, an issue we are going to tackle further down. The right panel of Figure 3 shows, based on Immigration and Naturalization Service data, that the number of

\footnotetext{
${ }^{13}$ Alternatively, in more rural places the Special Agricultural Worker (SAW) program provided permanent residency to aliens who could demonstrate they had 60 days of seasonal agricultural work experience in qualifying crops from May 1985 to May 1986. Nearly 1.3 million people applied for the SAW program.
} 
yearly deportations fell immediately after the IRCA, and started growing again in 1990, which is something we are going to come back shortly.

The second feature that we exploit is that the distribution of applicants across US cities was quite uneven. Not only it is more likely to find undocumented immigrants in places with large numbers of immigrants, in such places immigrants are also more likely to live in segregated neighborhoods, which makes it even easier for criminals to target such groups.

The MSA-NCVS version of the US victimization survey can be linked with the US Census, which has information on the legal status of immigrants, and also asks respondents whether they were residing in the United States 5 years earlier. Those are the two main eligibility conditions for the IRCA, which can be used to predict not just the number of applicants in a given MSA but also the fraction of Hispanics who are eligible to apply, which is an essential part of our model, corresponding to the $\gamma$ parameter in Section 2 .

In order to assess whether the Census can be used to predict the eligibility rate, in Figure 4 we correlate the predicted number of eligible immigrants (from the Census) with the number of actual applicants (from the IRCA administrative files). There is a very strong correlation, even if the none of the Censuses corresponds to the year the IRCA took place ${ }^{14}$ Since population estimates would be based on the Census the figure implies that the fraction of eligible immigrants would also be very similar. While no Census data are available for the year the IRCA took place, Figure 5 shows that at the MSA level the estimated fraction of eligible immigrants based on the 1980 Census are very similar to the ones based on the 1990 Census. This is driven by the fact that migration flows across different regions tend to be persistent over time.

\footnotetext{
${ }^{14}$ We use the $\log$ to make sure that such relationship is not driven by outliers.
} 
We use the predicted fraction of eligible immigrants of Hispanic origin to separate "low" from "high undocumented Hispanic immigration" cities. The exact eligibility rates can be seen in Table 2, where numbers in bold indicate MSAs in the top tercile in terms of fraction of undocumented Hispanics (first column). The city with the largest fraction of undocumented immigrants of Hispanic origin is Miami, Florida, followed by several Californian cities (Los Angeles, San Diego, and San Francisco). On the other side of the spectrum we find cities like Columbus, Ohio, or Pittsburgh, Pennsylvania, where the fraction is predicted to be close to zero. The remaining columns show the estimated

\section{Reporting Behavior, Victimization, and Legal Sta- \\ tus}

\subsection{Identification Strategy}

We model two different behaviors, the victims' reporting behavior as a function of whether they are legal immigrants or not, and the criminals' "ethnic targeting" behavior as a function of whether there is a large or small fraction of undocumented immigrants in the city (large or small $\gamma$ ), and we allow these behaviors to change with the IRCA.

Right before the IRCA we know that at least 3 million undocumented immigrants resided in the United States (the applicants), while after the IRCA an estimated flow of 800 thousand undocumented immigrants would enter the country every year (Warren and Warren, 2013). We also know that by the 1990 the estimated stock of undocumented immigrants had already reached 3.5 million (Warren and Warren 
(2013)). This implies that the IRCA effect should be a short-lived, as the stock of eligible migrants would quickly mix with the new flows of ineligible migrants Orrenius and Zavodny, 2003). For this reason in most regressions we simply exclude 1989 and 1990 from our regressions (though we do show the entire evolution of reporting and victimization rates including those two years, and including the two years does not significantly alter the results).

\subsubsection{Reporting Behavior}

Our theoretical model predicts that undocumented immigrants should increase their reporting following the IRCA, while natives should not. This leads to an empirical strategy where we compare the indicator variable for reporting a crime to the police $(R=0,1)$ depending on Hispanic $(H=1)$ and the non-Hispanic $(H=0)$ origin

of the victim in the two IRCA amnesty years, 1987 and 1988, with those before $(P R E=1981-1986)$ and after $(P O S T=1989-1994)$ the amnesty:

$$
R_{i t}=\beta^{P O S T} H_{i} \times P O S T_{t}+\beta^{P R E} H_{i} \times P R E_{t}+\beta^{H} H_{i}+\xi^{\prime} X_{i}+\epsilon_{i}
$$

The vector of regressors $X_{i}$ contains year and MSA fixed effects, and in some specifications crime-type fixed effects, as well as MSA specific time trends. Errors can be correlated across individuals living in the same MSA in a given year.

Given that from the victims' perspective the aim is to estimate these difference-indifferences conditional on being an IRCA applicant $A$ as opposed to just an Hispanic immigrant $H$, the estimates are subject to misclassification bias. On one side, not all Hispanics were eligible and applied for the amnesty, $P(A=1 \mid H=1)=\gamma<1$, on the other side, some non-Hispanic might also have applied, or $P(A=0 \mid H=0)=q<1$. 
Since most eligible applicants are believed to have applied (which is unsurprising given the incentives of becoming legalized), these errors stem from Hispanics who who entered the country after January 1, 1982 (they had been resident for less than 5 years at the time of the IRCA), as well as from those who were already US citizen by the time of the IRCA.

The misclassification probabilities $1-\gamma$ and $1-q$ are known to bias the results towards zero (Aigner, 1973). ${ }^{15}$ As we discussed in the Data section, using the Census we can compute the probability that someone of Hispanic origin is not only an undocumented immigrant but also eligible (and most likely applied) for the amnesty. We can also compute the probability that a non-Hispanic is eligible for the amnesty. The last four Columns of Table 2 show the fraction of eligible immigrants for Hispanics and non-Hispanics predicted based on the 1980 and 1990 Census. The fraction for non-Hispanics is an estimate of $1-q$, while for Hispanics it is an estimate of $\gamma$. Across all States, the estimated $q$ is between 97 and 98 percent, while the estimated $p$ is between 20 and 25 percent. Since the differences-in-differences are downward biased by a factor equal to $\gamma+q-1$, they have to be inflated by a factor that lies between 4 and 5 . Since the difference-in-differences estimate is going to be more precisely estimated in MSAs with a sufficient number of illegal Hispanics we also provide separate estimates depending on the presence of Hispanics and illegal Hispanics.

\footnotetext{
${ }^{15}$ Assuming that conditional on the application status Hispanic origin does not matter, or $E(R \mid H, A)=E(R \mid A)$ we have that

$$
\begin{aligned}
& E(R \mid H=1, T=t)=\gamma E(R \mid A=1, T=t)+(1-\gamma) E(R \mid A=0, T=t) \\
& E(R \mid H=0, T=t)=q E(R \mid A=0, T=t)+(1-q) E(R \mid A=1, T=t) .
\end{aligned}
$$

Taking a difference, and rearranging we get that

$$
E(R \mid H=1, T=t)-E(R \mid H=0, T=t)=[\gamma+q-1][E(R \mid A=1, T=t)-E(R \mid A=0, T=t)] .
$$

Taking a difference of this difference across different $T$ s we get that the difference-in-difference is still biased by the factor $\gamma+q-1$.
} 


\subsubsection{Victimization Behavior}

According to our model Hispanics are estimated to be victimized at lower rates following the IRCA, and the changes are predicted to be increasing in the share $\gamma$ of eligible immigrants in the MSA. Victimization rates against non-Hispanics might increase or decrease depending on the degree of spillovers in victimization across ethnicity (depending on $\xi$ ). For this reason the ideal difference-in-differences strategy compares victimization rates of individuals of Hispanic origin in places with large and small $\gamma \mathrm{s}$. We compare victimization rates in MSAs in the top tercile of $\gamma$ with those in the bottom two, though we also provide a full spectrum of robustness checks around these thresholds.

Unlike what happens for reporting, predictions are about differences based on ethnicity rather than IRCA eligibility, which implies that the estimates do not need to be adjusted for misclassification. The difference-in-differences model in victimization $(V=0,1)$ which is run separately for Hispanics and non-Hispanics is:

$$
V_{i t}=\beta^{P O S T} T O P(\gamma)_{i} \times P O S T_{t}+\beta^{P R E} T O P(\gamma)_{i} \times P R E_{t}+\xi^{\prime} X_{i}+\epsilon_{i}
$$

The indicator variable $\operatorname{TOP}(\gamma)_{i}$ indicates whether the individual resides in a MSA within the top tercile of the fraction of IRCA eligible undocumented immigrants of Hispanic origin over the entire Hispanic population. For the top tercile $\gamma$ averages 16.8 percent, while it averages 8.8 percent for the bottom two terciles. When we compute the difference-in-differences for the full range of different percentiles we combine the two coefficients $\beta^{P O S T}$ and $\beta^{P R E}$ into one $\beta^{P O S T \mid P R E}{ }^{16}$ The regressors $X_{i}$ contain year and MSA fixed effects, and in some specifications MSA specific time trends. We

\footnotetext{
${ }^{16}$ The regression becomes $V_{i t}=\beta^{P O S} T \mid P R E T O P(\gamma)_{i} \times\left(P O S T_{t}+P R E_{t}\right)+\xi^{\prime} X_{i}+\epsilon_{i}$.
} 
allow errors to be correlated across individuals living in the same MSA in a given year.

\subsection{Results}

\subsubsection{Reporting Rates}

The evolution of the differences in reporting rates between Hispanics and non-Hispanics are shown in the left panel of Figure $6{ }^{17}$ The right panel refers to MSAs with a large fraction of undocumented immigrants of Hispanic origin. The first thing to notice is that in communities with many undocumented immigrants reporting rates for Hispanics and non-Hispanics differ by about 5.5 percentage points (33.2 versus 38.7 percent). Later we will see that in MSAs with few undocumented Hispanics natives and immigrants have very similar reporting rates. In both panels the only years where the reporting rates are quite close to each other are 1987, 1988 and 1989. Then they start diverging again, in line with growing numbers of undocumented Hispanics who keep on entering the country. It is comforting to notice that the figure shows no pre-trends in the difference between Hispanics and Non-Hispanics, which is a necessary condition for the appropriateness of the difference-in-differences strategy.

Assuming that the reporting rate of legalized immigrants is the same as the one for natives one can use $\gamma$ to compute the unobserved reporting rate of illegal Hispanics. The overall Hispanic reporting rate is equal to a weighted average of reporting rates of legal Hispanics $(0.387)$ and illegal Hispanics $\left(\rho_{p, a}\right.$ in the notation of the model), where the weights are given by the $p=0.20$ and $1-p: 0.332=0.20 \rho_{p, a}+0.80 \times 0.387$. Solving for the reporting rate of illegal Hispanic immigrants $\rho_{p, a}=11.2$ percent.

\footnotetext{
${ }^{17}$ The raw series for each group is shown in Figure 9.
} 
Illegal immigrants who are victimized appear to be almost four times less likely to report a crime (11.2 percent versus 38.7 percent). The observed difference in reporting rates shrinks to 1.5 percentage points in 1987 and 1988. The difference-indifferences estimate in reporting rates is about 4 percentage points. When inflated by a factor of 5 (one over $p$ ), the estimate implies that reporting rates among recently legalized immigrants increase by about 20 percentage points, almost as large as those of non-Hispanic individuals (almost all of whom are legal citizens).

Whether these differences are statistically significant and robust when controlling for potential confounders is evidenced in Table 3 . We estimate Equation 5 using a linear probability model ${ }^{18}$ In the first three columns we do not separate MSAs into those with small and large Hispanic communities but add more and more confounders (first year and MSA dummies, then socioeconomic variables, and, finally, crime dummies). The difference-in-differences are always negative and on average close to 3 percentage points. The post-effects are significant while the pre-effects are not. Adding potential confounders slightly lowers the negative effect on reporting of being Hispanic. When focussing on MSAs with large fraction of Illegal Hispanics the estimates become much more precise. The same is true when focussing on MSAs with large fraction of Hispanics, whether illegally residing in the country or not. The differences-in-differences are all negative and significant, and are not too far from the 4 percentage points differences that we discussed when looking at Figure 9 .

Table 4 shows that there are almost no differences in the effects across economic crimes (theft, burglaries, robberies and other crimes), while the estimates appear to be more noisy for violent ones (robbery and assault). Most estimates based on

\footnotetext{
${ }^{18}$ In order to reduce the misclassification error we exclude the two years following the IRCA from the regression analysis (1989 and 1990). As from the evidence shown in the Figure, adding the 1989 to the IRCA years slightly increases the effect while adding also the 1990 slightly reduces the effect.
} 
individual crime types are negative, though statistical power becomes an issue.

\subsubsection{Victimization Rates}

The left panel of Figure 7 shows the difference in Hispanic victimization rates between MSAs with large and small $\gamma \mathrm{s}{ }^{19}$ In most years victimization rates of Hispanics are significantly larger in MSAs in the top tercile vs. MSAs in the bottom two terciles in the fraction of undocumented immigrants of Hispanic origin. The only two years where victimization rates are aligned are 1987 and 1988. Yet, there is evidence of a decreasing pre-trend in the differences between MSAs with large and small $\gamma \mathrm{s}$. For this reason, later in the regressions, we control for MSA specific trends. There are no apparent changes for non-Hispanics, and also no evidence of pre-trends.

Estimating Equation 6 using a linear probability model of victimization, we find similar effects to the ones shown in the figures (see Table 5). Comparing victimization probabilities of Hispanics, depending on whether they live in MSAs with a small or a large fraction of undocumented immigrants, both before, during, and after the IRCA, we find evidence that during the IRCA years victimization rates dropped by about 3 percentage points ( -30 percent). The first three columns show that the results are robust to various controls (age, gender, number of household members, and income). Adding MSA level time trends in Column 3 only one of the two differencein-differences remains significant. The last three columns show that there is no clear evidence with respect to native victims.

Since the treatment and control separation around the tercile is arbitrary, in Figure 8 we test whether the effects are robust to a different choice of treatment and control MSAs. Each dot corresponds to a separate difference-in-differences in victimization

\footnotetext{
${ }^{19}$ The raw series for each group is shown in Figure 10
} 
rates among Hispanics (vertical caps shows the 95 percent confidence intervals). There are a total of 41 MSAs and starting from the left we use the bottom 28 MSAs $(2 / 3)$ in terms of $\gamma$ as our control cities and only the top 2 MSAs as our treatment cities. Then as one moves to the right more and more MSAs are added to the treatment group in descending order with respect to $\gamma$. Once the 13th MSA is added to the treatment group, MSAs that used to be in the control group are added to the treatment group. We stop when the treatment group contains 3/4 of the MSAs. The difference-indifferences is decreasing as one adds MSAs with a lower fraction of undocumented immigrants within the Hispanic population, but the effects are significant all the way to the 28 th MSA, where $2 / 3$ of the MSA are in the treatment group and $1 / 3$ are in the control group.

The results are robust to the exclusion of the first two years before the IRCA, 1984 and 1985 (see Column 1 of Table 6), and to the exclusion of Los Angeles (Column 2) or New York City (Column 3). The last 4 columns show that in line with the reporting results the changes in victimization show up for both violent and economic crimes.

\subsubsection{Summary of the Results}

Wrapping up, we find evidence that following the IRCA Hispanic victims became more likely to report crimes to the police, especially in MSAs where they were more likely to be undocumented. Taking into account the large degree of misclassification, the changes are sizable, increasing by a factor of three to four their reporting rates. When it comes to victimization patterns, during the IRCA Hispanics become less likely to be victimized in communities where they are very likely to have been legalized (large $\gamma$ ). In line with the model's predictions with intermediate $\xi$ (probability of targeting 
the wrong ethnic group), there is no evidence of crime displacement against nonHispanics.

\section{Conclusions}

We provide evidence that out of fear of deportation undocumented immigrants are considerably less likely to report crimes to the police compared to natives (11 percent against 38 percent). This implies that the estimated 11.3 million undocumented immigrants are unable to safeguard their fundamental right to protect their property and their human right to security.

The 1986 US amnesty that provided legal status to 2.7 million immigrants, mainly of Hispanic origin, allows for a difference-in-differences strategy that deals with the issue that in victimization surveys information about legal status is unavailable. It also deals with the issue that legal status is typically endogenous. Right after the amnesty Hispanic immigrants become considerably more likely to report a crime to the police. Taking into account that not all Hispanic immigrants are undocumented, the changes in reporting rates are close to 20 percentage points. These are massive changes, with important implications for the wellbeing of undocumented migrants.

In line with the predictions of a simple model of crime, with their lower reporting rates, immigrants become preferred victims of crime. Amnesties appear to limit the targeting of undocumented immigrants.

While it is difficult to assess the external validity of the IRCA amnesty, our results are likely to carry over to recent undocumented immigrants residing in the United States right now, half of which are estimated to be Mexican. In recent years US lawmakers have partially addressed the issue. In order to favor the reporting of un- 
documented immigrants, in 2008 the US congress approved a special VISA program ("U nonimmigrant status"). According to this program, every year victims of serious offences that are willing to work with local enforcement authorities are given temporary legal status and work eligibility in the United States. The U-1 Visa is unlikely to be sufficient to protect immigrants' right to property and security. On one side only violent crimes are considered. On the other side, the VISA is only temporary, up to 4 years, which might not be enough to incentivize immigrants to report the crime to the police. And, finally, the number of $U$ visas is capped at 10,000 .

Another open question is whether our results are generalizable to other countries. This should depend on whether, like in the US, immigrants are at risk of deportation when reporting a crime. It also depends on whether criminals can somehow predict the legal status of their victims. In some US cities Hispanic immigrants are likely to be undocumented, but the same is true for African and Asian immigrants in several developed countries.

Our analysis has additional implications that are worth mentioning. It points out that investigating the consequences of amnesties by looking at reported crimes may have some important undesirable pitfalls. The increase in reporting might turn out to be a rise in crime rates even if the true crime rates decreased These effects should be carefully taken into account in the empirical investigation of amnesties, especially when the size of the illegal immigration is large. 


\section{References}

Dennis J Aigner. Regression with a binary independent variable subject to errors of observation. Journal of Econometrics, 1(1):49-59, 1973.

Emily Badger. What happened to the millions of immigrants granted legal status under ronald reagan? The Washington Post, November 26, 2014.

Scott R Baker. Effects of immigrant legalization on crime. The American Economic Review, 105(5):210-213, 2015.

Silvia Helena Barcellos. Legalization and the economic status of immigrants. 2010.

Kelle Barrick. Latino confidence in the police: The role of immigration enforcement, assimilation, and immigration status. Journal of Ethnicity in Criminal Justice, 12 (4):289-307, 2014.

Brian Bell, Stephen Machin, and Francesco Fasani. Crime and immigration: Evidence from large immigrant waves. Review of Economics and Statistics, 95(4):1278-1290, 2013.

Milo Bianchi, Paolo Buonanno, and Paolo Pinotti. Do immigrants cause crime? Journal of the European Economic Association, 10(6):1318-1347, 2012.

George J Borjas. The economics of immigration. Journal of economic literature, 32 (4):1667-1717, 1994.

Jacob Bucher, Michelle Manasse, and Beth Tarasawa. Undocumented victims: An examination of crimes against undocumented male migrant workers. Southwest Journal of Criminal Justice, 7(2):159-179, 2010. 
Kristin F. Butcher and Anne M. Piehl. Cross-City Evidence on the Relationship between Immigration and Crime. Journal of Policy Analysis and Management, 17 (3):457-493, 1998 .

David Card. The impact of the Mariel boatlift on the Miami labor market. Industrial E Labor Relations Review, 43(2):245-257, 1990.

Mark E Correia. Determinants of attitudes toward police of latino immigrants and non-immigrants. Journal of Criminal Justice, 38(1):99-107, 2010.

Matthew Freedman, Emily Owens, and Sarah Bohn. Immigration, employment opportunities, and criminal behavior, 2013.

Nuno Garoupa. Optimal law enforcement when victims are rational players. In Conflict and Governance, pages 123-134. Springer, 2003.

Itzhak Goldberg and Frederick C Nold. Does Reporting Deter Burglars? An Empirical Analysis of Risk and Return in Crime. The Review of Economics and Statistics, pages 424-431, 1980.

Heike Goudriaan, Karin Wittebrood, and Paul Nieuwbeerta. Neighbourhood characteristics and reporting crime effects of social cohesion, confidence in police effectiveness and socio-economic disadvantage. British Journal of Criminology, 46(4): 719-742, 2006.

Carmen M Gutierrez and David S Kirk. Silence speaks the relationship between immigration and the underreporting of crime. Crime \&f Delinquency, pages 1-25, 2015. 
Sherrie A. Kossoudji and Deborah A. Cobb-Clark. Coming out of the Shadows: Learning about Legal Status and Wages from the Legalized Population. Journal of Labor Economics, 20(3):598-628, 2002.

Jens Manuel Krogstad and Jeffrey S Passel. 5 Facts about Illegal Immigration in the US. Pew Research Center, 2014.

Fernando Lozano and Todd Sorensen. The labor market value to legal status. Iza working paper, Bonn, Germany: Institute for the Study of Labor, 2011.

Giovanni Mastrobuoni and Paolo Pinotti. Legal status and the criminal activity of immigrants. American Economic Journal: Applied Economics, 7(2):175-206, 2015.

Cecilia Menjívar and Cynthia Bejarano. Latino immigrants' perceptions of crime and police authorities in the United States: A case study from the Phoenix metropolitan area. Ethnic and racial studies, 27(1):120-148, 2004.

Amalia R Miller and Carmit Segal. Do female officers improve law enforcement quality? Effects on crime reporting and domestic violence escalation, 2014.

Pia M Orrenius and Madeline Zavodny. Do amnesty programs reduce undocumented immigration? evidence from irca. Demography, 40(3):437-450, 2003.

Anne Morrison Piehl. The Connection between Immigration and Crime. Hearing on comprehensive immigration reform: Impact of immigration on states and localities, Committee on the Judiciary; Subcommittee on Immigration, Citizenship, Refugees, Border Security, and International Law, 2007.

Paolo Pinotti. Clicking on heaven's door: The effect of immigrant legalization on crime. Baffi Center Research Paper, (2014-154), 2014. 
Paolo Pinotti. Immigration enforcement and crime. The American Economic Review, $105(5): 205-209,2015$.

Robert Warren and John Robert Warren. Unauthorized immigration to the united states: annual estimates and components of change, by state, 1990 to 2010. International Migration Review, 47(2):296-329, 2013. 


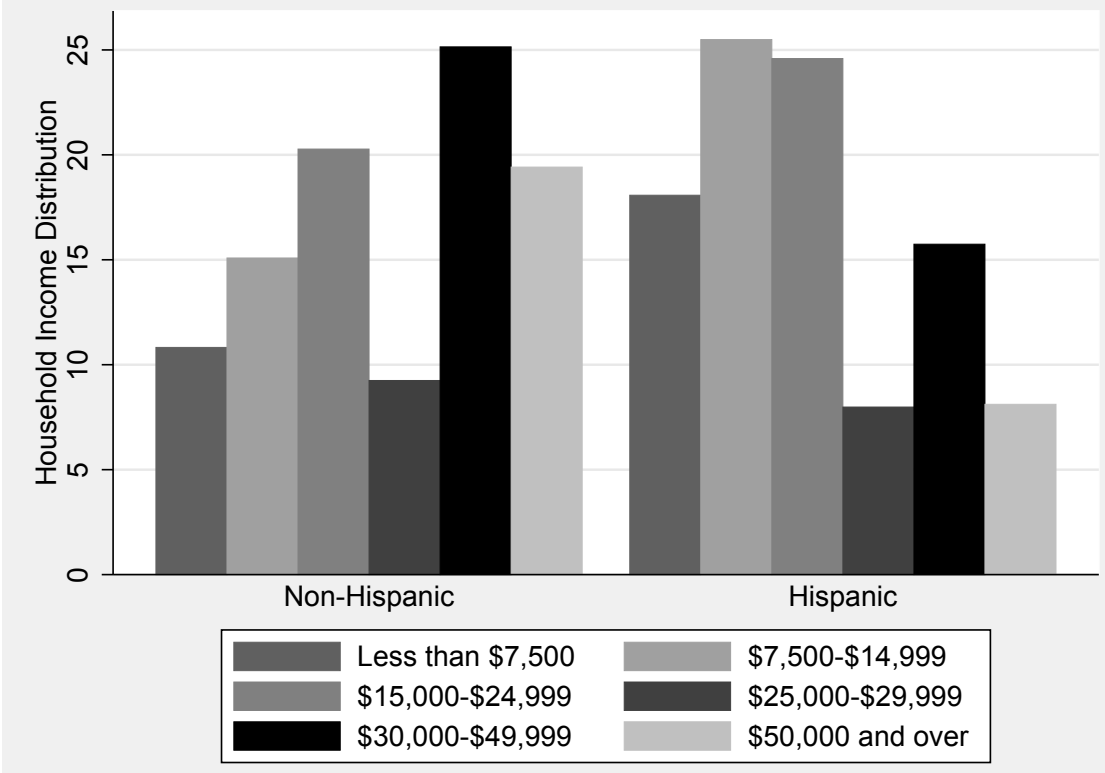

Figure 2: Distribution of Household Income by Hispanic Origin 

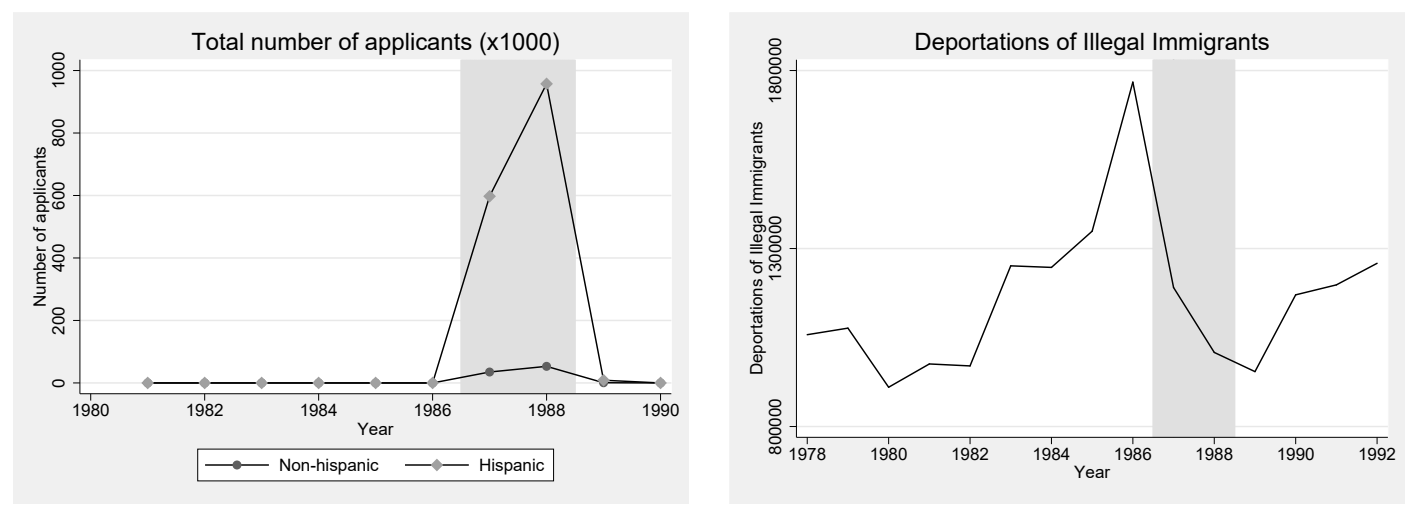

Figure 3: IRCA Applicants and Deportations of Unauthorized Immigrants

Notes: The number of NCVS-MSA IRCA applicants are based on authors' calculation by matching the Legalization Summary Public Use Tape with the NCVS survey. The number of deportations refer to the entire US, and are based on the Immigration and Naturalization Service data.

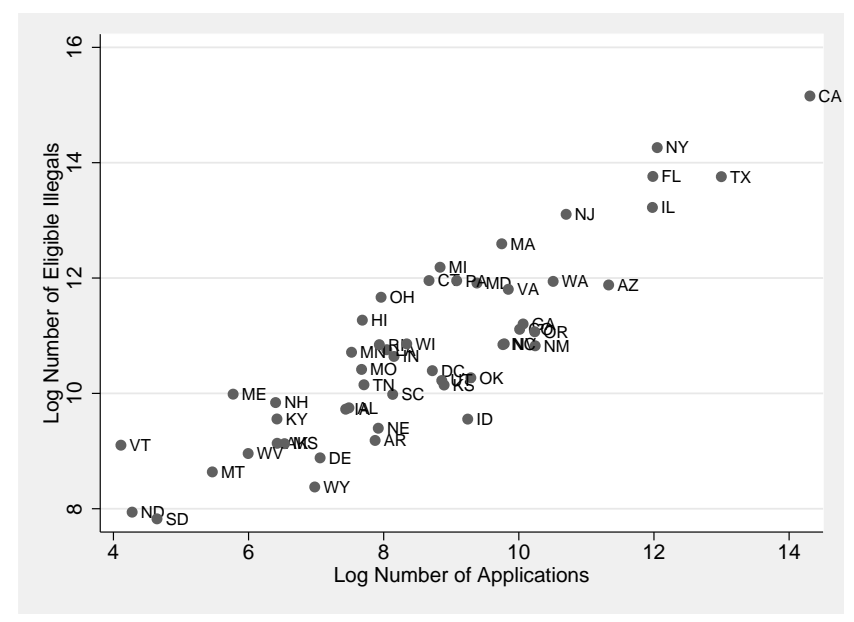

Figure 4: IRCA Applicants against their Predicted Number According to the Census

Notes: The log number of eligible immigrants in the Census is based on the available eligibility criteria. The log number of applicants is based on the Legalization Summary Public Use Tape. 


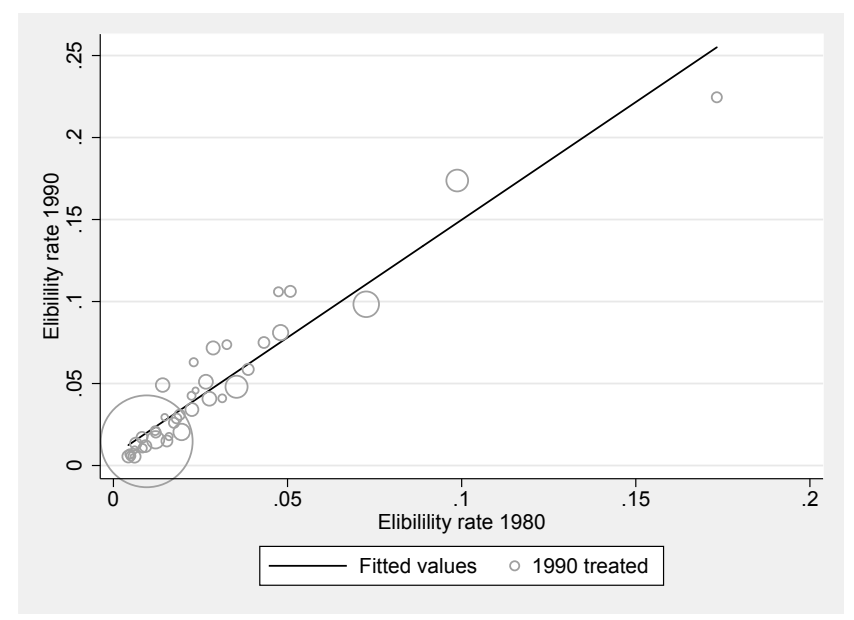

Figure 5: Predicted Fraction of Eligible According to the Census

Notes: The fraction of eligible immigrants in the population in the Census is based on the known eligibility criteria. The circles are proportional to the size of the MSA population.
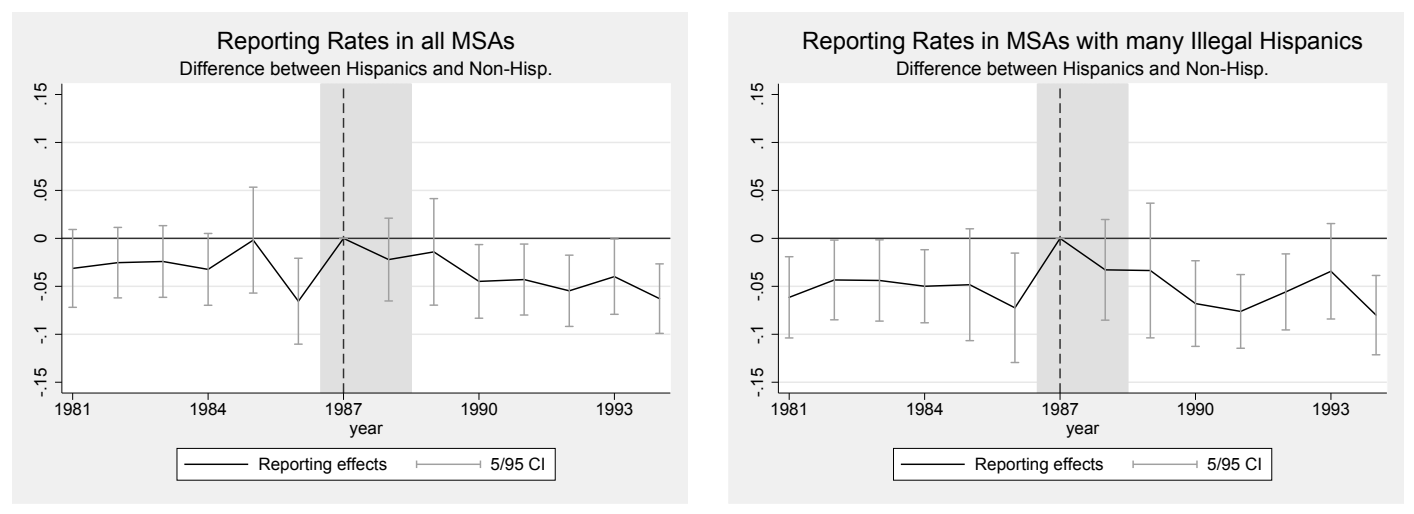

Figure 6: Difference-in-differences in reporting rates between Hispanics and nonHispanics in all MSAs and in those with a large fraction of undocumented Hispanics (top one third).

Notes: Based on NCVS data matched with the 1980 Census. 
Hispanic Victimization Rates

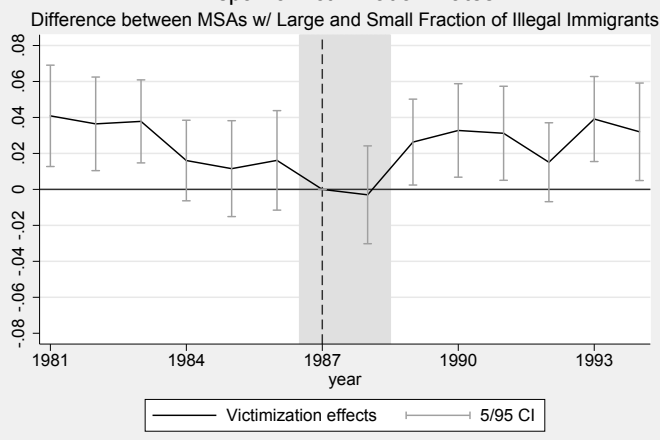

Non-Hisp Victimization Rates

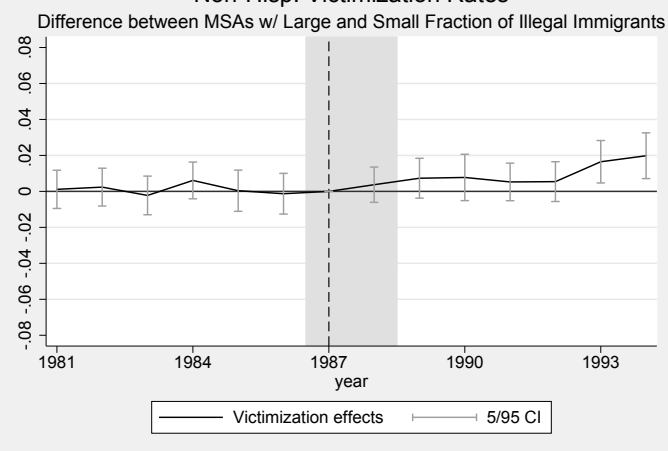

Figure 7: Difference-in-differences in victimization rates of Hispanics (left) and nonHispanics (right) in MSAs with the top third and bottom two-thirds fraction of undocumented Hispanics.

Notes: Based on NCVS data matched with the 1980 Census. 


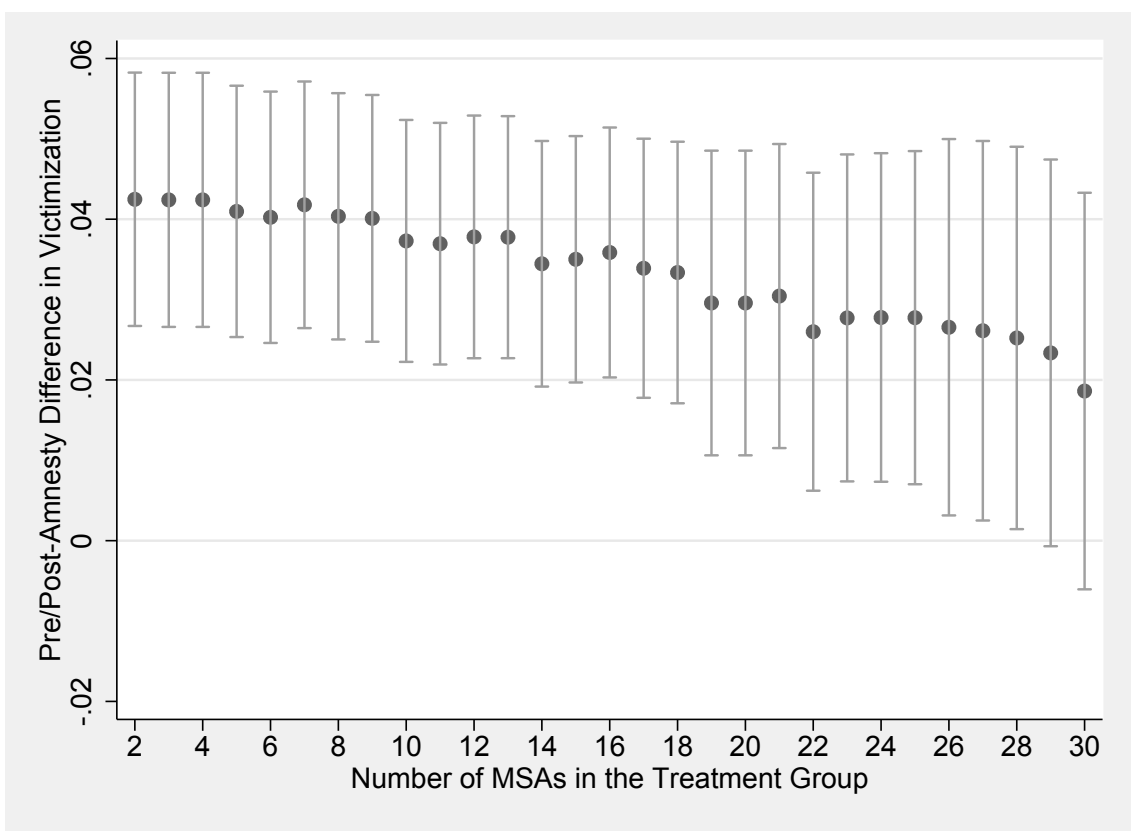

Figure 8: Difference-in-differences in Victimization Rates amongst Hispanics

Notes: Each dot corresponds to a separate difference-in-differences in victimization rates among Hispanics. Vertical caps represent the corresponding 95 percent confidence intervals. There are a total of 41 MSAs. Initially the control cities are the bottom $2 / 3$ or 28 in terms of $\gamma$. MSAs are added to the treatment group starting from top in terms of $\gamma$. Once the 13th MSA is added to the treatment group previous control MSAs switch to the treatment MSAs. 
Table 1: Summary Statistics

\begin{tabular}{|c|c|c|c|c|c|c|}
\hline \multirow[b]{3}{*}{ Reported the crime } & \multicolumn{2}{|c|}{ Victims } & \multicolumn{2}{|r|}{ All } & \multirow[t]{2}{*}{ Min } & \multirow[t]{2}{*}{ Max } \\
\hline & Mean & Std. Dev. & Mean & Std. Dev. & & \\
\hline & 0.39 & 0.49 & - & - & 0 & 1 \\
\hline Crime victim & 1.00 & 0.00 & 0.11 & 0.31 & 1 & 1 \\
\hline Hispanic & 0.11 & 0.31 & 0.10 & 0.30 & 0 & 1 \\
\hline White & 0.84 & 0.36 & 0.86 & 0.34 & 0 & 1 \\
\hline Year & 1987 & 4 & 1987 & 4 & 1981 & 1994 \\
\hline Pre-IRCA & 0.49 & 0.50 & 0.47 & 0.50 & 0 & 1 \\
\hline Post-IRCA & 0.38 & 0.49 & 0.39 & 0.49 & 0 & 1 \\
\hline Age 18-24 & 0.21 & 0.41 & 0.14 & 0.35 & 0 & 1 \\
\hline Age $25-29$ & 0.17 & 0.37 & 0.12 & 0.33 & 0 & 1 \\
\hline Age $29-34$ & 0.15 & 0.35 & 0.12 & 0.33 & 0 & 1 \\
\hline Age 35-39 & 0.12 & 0.33 & 0.11 & 0.31 & 0 & 1 \\
\hline Age $40-49$ & 0.16 & 0.37 & 0.17 & 0.37 & 0 & 1 \\
\hline Age $50-59$ & 0.09 & 0.29 & 0.13 & 0.33 & 0 & 1 \\
\hline Female & 0.53 & 0.50 & 0.54 & 0.50 & 0 & 1 \\
\hline N. obs. & \multicolumn{2}{|c|}{114,079} & \multicolumn{2}{|c|}{$1,052,603$} & & \\
\hline
\end{tabular}

Notes: Based on NCVS data matched with the 1980 Census. 
Table 2: Fraction of Hispanic Population by MSA (Illegal and Total)

\begin{tabular}{|c|c|c|c|c|c|c|}
\hline \multirow[b]{4}{*}{1} & \multirow[b]{3}{*}{ MSA } & \multirow{3}{*}{$\begin{array}{c}\text { Predicted Fraction of } \\
\text { Eligible and Hispanic (NCVS) }\end{array}$} & \multicolumn{4}{|c|}{ Fraction that would be eligible for the IRCA amnesty } \\
\hline & & & \multicolumn{2}{|c|}{ Census Year 1980} & \multicolumn{2}{|c|}{ Census Year 1990} \\
\hline & & & Non-Hispanics & Hispanics & Non-Hispanics & Hispanics \\
\hline & Anaheim-Santa Ana, CA & $2.25 \%$ & $2.58 \%$ & $21.35 \%$ & $5.68 \%$ & $29.81 \%$ \\
\hline 2 & Atlanta, GA & $0.09 \%$ & $0.63 \%$ & $15.06 \%$ & $1.40 \%$ & $19.35 \%$ \\
\hline 3 & Baltimore, MD & $0.02 \%$ & $0.88 \%$ & $8.71 \%$ & $1.03 \%$ & $10.04 \%$ \\
\hline 4 & Boston, MA-NH & $0.18 \%$ & $2.48 \%$ & $16.44 \%$ & $3.34 \%$ & $18.93 \%$ \\
\hline 5 & Charlotte-Gastonia-Rock Hill, NC-SC & $0.15 \%$ & $0.50 \%$ & $12.71 \%$ & $0.78 \%$ & $14.79 \%$ \\
\hline 6 & Chicago, IL & $0.98 \%$ & $2.05 \%$ & $22.48 \%$ & $2.40 \%$ & $26.55 \%$ \\
\hline 7 & Cincinnati, OH-KY-IN & $0.03 \%$ & $0.45 \%$ & $7.21 \%$ & $0.57 \%$ & $10.53 \%$ \\
\hline 8 & Cleveland, Lorain, Elyria, $\mathrm{OH}$ & $0.04 \%$ & $1.48 \%$ & $5.73 \%$ & $1.32 \%$ & $6.11 \%$ \\
\hline 9 & Columbus, $\mathrm{OH}$ & $0.00 \%$ & $0.57 \%$ & $3.83 \%$ & $0.48 \%$ & $1.85 \%$ \\
\hline 10 & Dallas, TX & $0.52 \%$ & $0.62 \%$ & $11.65 \%$ & $1.78 \%$ & $24.62 \%$ \\
\hline 11 & Denver, CO & $0.17 \%$ & $0.94 \%$ & $3.15 \%$ & $1.38 \%$ & $7.03 \%$ \\
\hline 12 & Detroit, MI & $0.12 \%$ & $1.81 \%$ & $10.61 \%$ & $1.87 \%$ & $7.62 \%$ \\
\hline 13 & Fort Lauderdale, FL & $1.00 \%$ & $1.72 \%$ & $18.96 \%$ & $4.47 \%$ & $23.78 \%$ \\
\hline 14 & Fort Worth-Arlington, TX & $1.54 \%$ & & & $1.51 \%$ & $17.90 \%$ \\
\hline 15 & Houston, TX & $1.26 \%$ & $1.07 \%$ & $13.22 \%$ & $2.43 \%$ & $26.18 \%$ \\
\hline 16 & Kansas City, MO-KS & $0.04 \%$ & $0.35 \%$ & $6.20 \%$ & $0.49 \%$ & $9.06 \%$ \\
\hline 17 & Los Angeles-Long Beach, CA & $5.54 \%$ & $3.62 \%$ & $28.75 \%$ & $7.93 \%$ & $35.50 \%$ \\
\hline 18 & Miami, FL & $13.46 \%$ & $2.87 \%$ & $42.36 \%$ & $8.27 \%$ & $37.44 \%$ \\
\hline 19 & Minneapolis-St. Paul, MN-WI & $0.04 \%$ & $0.61 \%$ & $6.80 \%$ & $1.23 \%$ & $9.58 \%$ \\
\hline 20 & Nassau-Suffolk, NY & $0.33 \%$ & $1.87 \%$ & $14.16 \%$ & $2.59 \%$ & $18.10 \%$ \\
\hline 21 & New York, NY & $2.05 \%$ & $5.25 \%$ & $18.06 \%$ & $6.67 \%$ & $20.95 \%$ \\
\hline 23 & Newark, NJ & $0.74 \%$ & $2.69 \%$ & $22.24 \%$ & $4.02 \%$ & $20.64 \%$ \\
\hline 24 & Norfolk-Virginia Beach-Newport News, VA & $0.09 \%$ & $0.76 \%$ & $5.57 \%$ & $1.02 \%$ & $7.59 \%$ \\
\hline 25 & Oakland, CA & $0.60 \%$ & $1.71 \%$ & $6.40 \%$ & $1.46 \%$ & $6.87 \%$ \\
\hline 26 & Orlando, FL & $0.31 \%$ & $0.88 \%$ & $16.80 \%$ & $2.01 \%$ & $12.47 \%$ \\
\hline 27 & Philadelphia, PA-NJ & $0.06 \%$ & $1.09 \%$ & $5.40 \%$ & $1.33 \%$ & $5.84 \%$ \\
\hline 28 & Phoenix-Mesa, AZ & $0.68 \%$ & $0.93 \%$ & $8.28 \%$ & $1.20 \%$ & $13.51 \%$ \\
\hline 29 & Pittsburgh, PA & $0.00 \%$ & $0.57 \%$ & $6.00 \%$ & $0.55 \%$ & $6.84 \%$ \\
\hline 30 & Portland-Vancouver, OR-WA & $0.10 \%$ & $1.07 \%$ & $8.90 \%$ & $1.76 \%$ & $14.62 \%$ \\
\hline 31 & Riverside-San Bernardino, CA & $1.49 \%$ & $1.56 \%$ & $11.24 \%$ & $2.89 \%$ & $22.81 \%$ \\
\hline 32 & Sacramento, CA & $0.66 \%$ & $1.37 \%$ & $11.06 \%$ & $3.24 \%$ & $13.96 \%$ \\
\hline 33 & St. Louis, MO-IL & $0.02 \%$ & $0.39 \%$ & $5.64 \%$ & $0.44 \%$ & $7.43 \%$ \\
\hline 34 & San Antonio, TX & $2.31 \%$ & $0.62 \%$ & $6.57 \%$ & $1.14 \%$ & $7.54 \%$ \\
\hline 35 & San Diego, CA & $2.29 \%$ & $1.78 \%$ & $20.73 \%$ & $3.36 \%$ & $26.89 \%$ \\
\hline 36 & San Francisco, CA & $1.50 \%$ & $3.44 \%$ & $17.15 \%$ & $5.69 \%$ & $24.69 \%$ \\
\hline 37 & San Jose, CA & $1.25 \%$ & $3.28 \%$ & $13.27 \%$ & $8.06 \%$ & $20.00 \%$ \\
\hline 38 & Seattle-Bellevue-Everett, WA & $0.11 \%$ & $1.87 \%$ & $5.70 \%$ & $2.73 \%$ & $10.46 \%$ \\
\hline 39 & Tampa-St. Petersburg-Clearwater, FL & $0.61 \%$ & $1.07 \%$ & $13.78 \%$ & $1.66 \%$ & $15.18 \%$ \\
\hline 40 & Washington, DC-MD-VA-WV & $0.49 \%$ & $2.00 \%$ & $24.58 \%$ & $3.48 \%$ & $29.46 \%$ \\
\hline 41 & West Palm Beach-Boca Raton, FL & $0.67 \%$ & $1.46 \%$ & $22.92 \%$ & $3.01 \%$ & $25.02 \%$ \\
\hline Total & & $3.68 \%$ & $2.06 \%$ & $20.31 \%$ & $3.27 \%$ & $25.77 \%$ \\
\hline
\end{tabular}

Notes: The top ten MSAs in each ranking, which define the top tercile in the data, are shown in bold letters. The last four columns correspond to the $\gamma$ estimate from the two Censuses. The $\operatorname{TOP}(\gamma)$ indicator variable is based on the 1980 Census, and is equal to one for the MSAs that are in bold letters. 
Table 3: Reporting Regressions

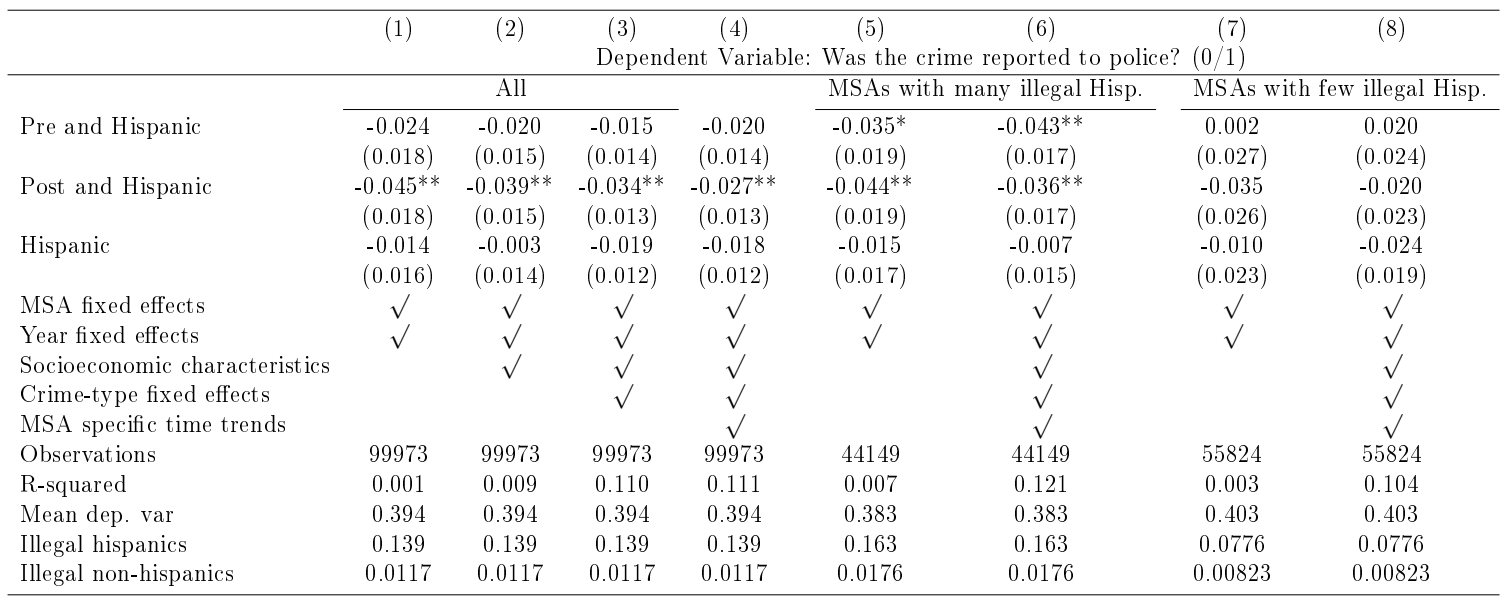

Notes: The socioeconomic variables include age group dummies, gender, number of household members, and dummies for household income categories. Clustered standard errors (by year and MSA) in parentheses: ${ }^{* * *} \mathrm{p}<0.01,{ }^{* *} \mathrm{p}<0.05,{ }^{*} \mathrm{p}<0.1$.

Table 4: Reporting Regressions by Crime Types

\begin{tabular}{lcccccc}
\hline & $(1)$ & $(2)$ & $(3)$ & $(4)$ & $(5)$ & $(6)$ \\
& \multicolumn{7}{c}{ Dependent Variable: } & Was the crime reported to police? $(0 / 1)$ \\
\hline Crime type & Violent & Economic & Robbery & Burglary & Theft & Assault \\
Pre and Hispanic & -0.074 & $-0.032^{*}$ & -0.077 & 0.011 & $-0.044^{*}$ & -0.045 \\
& $(0.045)$ & $(0.019)$ & $(0.065)$ & $(0.047)$ & $(0.023)$ & $(0.063)$ \\
Post and Hispanic & -0.031 & $-0.043^{* *}$ & -0.094 & -0.033 & -0.037 & 0.003 \\
& $(0.052)$ & $(0.019)$ & $(0.083)$ & $(0.051)$ & $(0.024)$ & $(0.067)$ \\
Hispanic & 0.036 & 0.002 & -0.037 & -0.049 & 0.005 & 0.053 \\
& $(0.043)$ & $(0.016)$ & $(0.060)$ & $(0.042)$ & $(0.021)$ & $(0.059)$ \\
Observations & 6558 & 37871 & 1863 & 7294 & 28714 & 4537 \\
Mean dep. var & 0.522 & 0.368 & 0.572 & 0.521 & 0.316 & 0.502 \\
R-squared & 0.031 & 0.015 & 0.105 & 0.041 & 0.013 & 0.026 \\
Illegal hispanics & 0.130 & 0.149 & 0.143 & 0.152 & 0.149 & 0.120 \\
Illegal non-hispanics & 0.0147 & 0.0161 & 0.0170 & 0.0162 & 0.0161 & 0.0139 \\
\hline
\end{tabular}

Notes: All regressions are restricted to MSAs with many undocumented immigrants of Hispanic origin. All regressions include MSA and year fixed effects, as well as age group dummies, gender, number of household members, and dummies for household income categories. Clustered standard errors (by year and MSA) in parentheses: ${ }^{* * *} \mathrm{p}<0.01,{ }^{* *} \mathrm{p}<0.05,{ }^{*} \mathrm{p}<0.1$. 


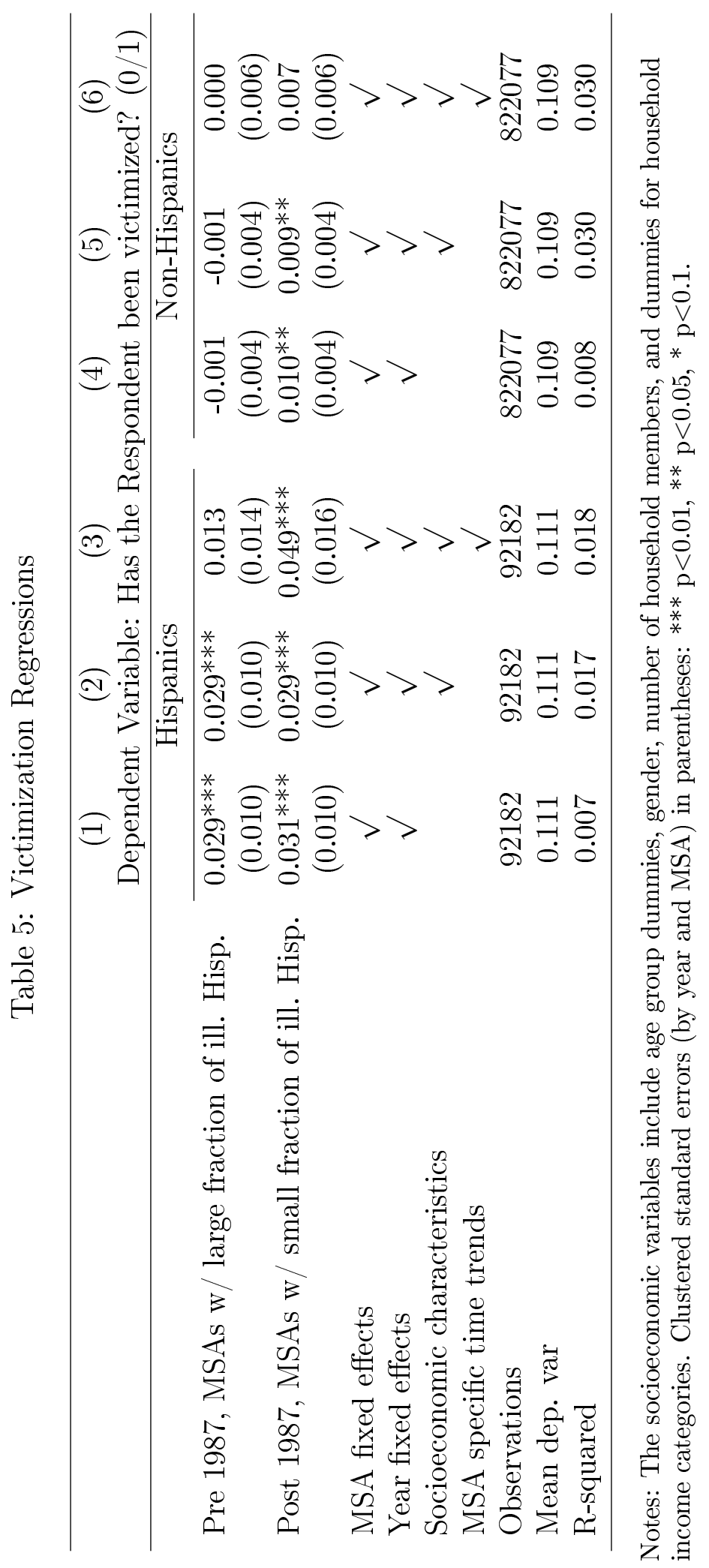




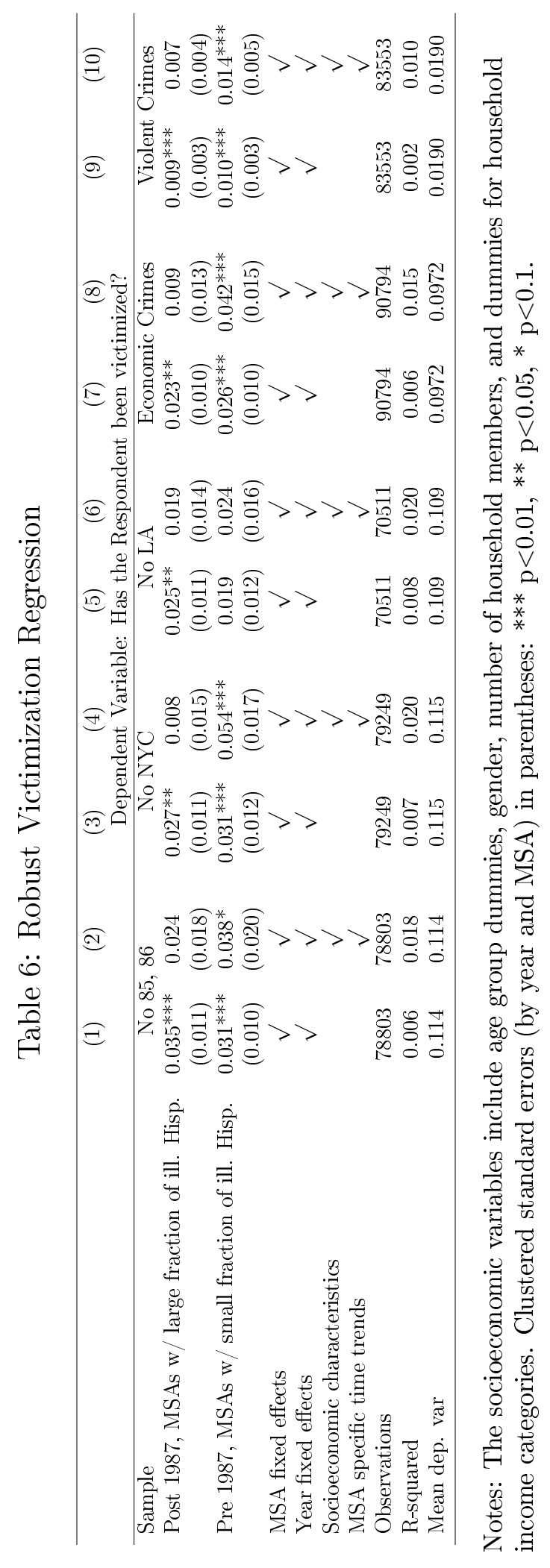




\section{A Mathematical Appendix}

Proof of Proposition 1. We first characterize how the amnesty impacts on the thresholds $\hat{\theta}_{p}, \hat{\theta}_{a}$ and $\bar{\theta}$ defined in the paper. This is shown in Claim 1 below where we let $\bar{\theta}^{\prime}, \hat{\theta}_{a}^{\prime}$ and $\hat{\theta}_{p}^{\prime}$ denote the thresholds after the amnesty.

Claim 1: an amnesty that legalizes a fraction $x \in(0,1]$ of immigrants increases $\hat{\theta}_{p}$ and $\hat{\theta}_{a}$ while reducing $\bar{\theta}$. The change in the thresholds is larger the higher is the initial share of undocumented immigrants.

Proof of Claim 1. Consider $\hat{\theta}_{p}$ and $\hat{\theta}_{p}^{\prime}$. Notice that $\hat{\theta}_{p}^{\prime}-\hat{\theta}_{p}=\frac{\xi\left(C\left(\bar{\rho}_{i}(x)\right)-C\left(\bar{\rho}_{i}\right)\right)}{\Pi\left(\bar{w}_{i}, \bar{w}_{n}\right)}>0$ since $\bar{\rho}_{i}(x)>\bar{\rho}_{i}$; hence the amnesty causes an increase in $\hat{\theta}_{p}$. Moreover, notice that:

$$
\frac{\partial\left(\hat{\theta}_{p}^{\prime}-\hat{\theta}_{p}\right)}{\partial \gamma}=\frac{\xi}{\Pi\left(\bar{w}_{i}, \bar{w}_{n}\right)}\left[C^{\prime}\left(\bar{\rho}_{i}(x)\right)(1-x)\left(\rho_{p, a}-\rho_{p, l}\right)-C^{\prime}\left(\bar{\rho}_{i}\right)\left(\rho_{p, a}-\rho_{p, l}\right)\right]>0
$$

provided that $\left(\rho_{p, a}-\rho_{p, l}\right)<(1-x)\left(\rho_{p, a}-\rho_{p, l}\right)<0$ and $C^{\prime}\left(\bar{\rho}_{i}(x)\right)<C^{\prime}\left(\bar{\rho}_{i}\right)$ by the concavity of the expected punishment function. Therefore, the increase in $\hat{\theta}_{p}$ caused by the amnesty is larger the higher the initial share of undocumented immigrants. Similar arguments can be used to show that the amnesty causes an increase in $\hat{\theta}_{a}$, a decrease in $\bar{\theta}$ and that both changes are more marked the larger $\gamma$.

Let $X_{i}^{\prime}$ and $X_{n}^{\prime}$ denote the number of criminals targeting the two groups after the amnesty. Let also

$$
\begin{aligned}
X & =X_{i}+X_{n}=\gamma\left(1-\hat{\theta}_{a}\right)+(1-\gamma+\phi)\left(1-\hat{\theta}_{p}\right), \\
X^{\prime} & =X_{i}^{\prime}+X_{n}^{\prime}=\gamma(1-x)\left(1-\hat{\theta}_{a}^{\prime}\right)+(1-\gamma+\phi+\gamma x)\left(1-\hat{\theta}_{p}^{\prime}\right),
\end{aligned}
$$

denote the overall level of crime without and with the amnesty, respectively. 
Notice that the amnesty reduces the overall level of crime:

$$
X^{\prime}-X=\gamma\left(\hat{\theta}_{a}-\hat{\theta}_{a}^{\prime}\right)+(1-\gamma+\phi)\left(\hat{\theta}_{p}-\hat{\theta}_{p}^{\prime}\right)+\gamma x\left(\hat{\theta}_{a}^{\prime}-\hat{\theta}_{p}^{\prime}\right)<0
$$

since $\hat{\theta}_{a}<\hat{\theta}_{a}^{\prime}$ and $\hat{\theta}_{p}<\hat{\theta}_{p}^{\prime}$ by Claim 1 and $\hat{\theta}_{a}^{\prime}<\hat{\theta}_{p}^{\prime}$ from $f\left(w_{p}, \rho_{p, l}\right)>f\left(w_{p}, \rho_{a, l}\right)$. Notice that the first two terms of expression (9) represent the reduction in crime due to the increased average reporting rate of immigrants; the last term, instead, is the reduced level of criminality related to the higher opportunity cost of becoming criminals experienced by the legalized immigrants.

Taking the derivative of expression (9), it is possible to check that the reduction in crime is greater the higher the initial share of undocumented immigrants:

$$
\begin{aligned}
\frac{\partial\left(X^{\prime}-X\right)}{\partial \gamma}= & \left(\hat{\theta}_{a}-\hat{\theta}_{a}^{\prime}\right)-\left(\hat{\theta}_{p}-\hat{\theta}_{p}^{\prime}\right)+x\left(\hat{\theta}_{a}^{\prime}-\hat{\theta}_{p}^{\prime}\right)+\gamma \frac{\partial\left(\hat{\theta}_{a}-\hat{\theta}_{a}^{\prime}\right)}{\partial \gamma} \\
& +(1-\gamma+\phi) \frac{\partial\left(\hat{\theta}_{p}-\hat{\theta}_{p}^{\prime}\right)}{\partial \gamma}+\gamma x \frac{\partial\left(\hat{\theta}_{a}^{\prime}-\hat{\theta}_{p}^{\prime}\right)}{\partial \gamma}<0 .
\end{aligned}
$$

Notice indeed that $\left(\hat{\theta}_{p}^{\prime}-\hat{\theta}_{a}^{\prime}\right)=\left(\hat{\theta}_{p}-\hat{\theta}_{a}\right)=\left[f\left(w_{p}, \rho_{p, l}\right)-f\left(w_{p}, \rho_{p, a}\right)\right] / \Pi\left(\bar{w}_{i}, \bar{w}_{n}\right)$; hence, the sum of the first two terms as well as the last term $\left(\hat{\theta}_{p}^{\prime}-\hat{\theta}_{a}^{\prime}\right.$ does not depend on $\gamma$ ) are null. The rest of the terms appearing in the above expression are all negative from Claim 1.

Confronting the number of criminals targeting natives with and without the amnesty:

$$
X_{n}^{\prime}-X_{n}=(1+\phi)\left(\bar{\theta}-\bar{\theta}^{\prime}\right)>0
$$

if follows that the the amnesty increases the number of criminals targeting natives. 
The derivative:

$$
\frac{\partial\left(X_{n}^{\prime}-X_{n}\right)}{\partial \gamma}=(1+\phi) \frac{\partial\left(\bar{\theta}-\bar{\theta}^{\prime}\right)}{\partial \gamma}>0
$$

which implies that the increase in the number of criminals targeting immigrants is more marked the higher the initial number of undocumented immigrants. Clearly, given the impact on $X$ (overall level of crime) and on $X_{n}$ (number of criminals targeting natives), the effect of the amnesty is to increase the share of criminals targeting natives; this effect is stronger the higher $\gamma$. As a consequence, the effect on the share of criminals targeting immigrants is opposite: it reduces after the amnesty and this variation is more marked the higher the initial share of undocumented immigrants.

Proof of Proposition 2. Using the expression for $X_{n}^{\prime}-X_{n}$ shown in the proof of Proposition 1 and computing the variation in the number of criminals targeting immigrants, $X_{i}^{\prime}-X_{i}=\gamma\left(\bar{\theta}^{\prime}-\bar{\theta}+\hat{\theta}_{a}-\hat{\theta}_{a}^{\prime}\right)+(1-\gamma+\phi)\left(\bar{\theta}^{\prime}-\bar{\theta}+\hat{\theta}_{p}-\hat{\theta}_{p}^{\prime}\right)+\gamma x\left(\hat{\theta}_{a}^{\prime}-\hat{\theta}_{p}^{\prime}\right)$, it follows that the change in crime to which immigrants are exposed amounts to:

$$
\begin{array}{r}
X_{i}^{\mathrm{ex} \prime}-X_{i}^{\mathrm{ex}}=\gamma\left[(2 \xi-1)\left(\bar{\theta}^{\prime}-\bar{\theta}\right)+\xi\left(\hat{\theta}_{a}-\hat{\theta}_{a}^{\prime}\right)\right] \\
+(1-\gamma+\phi)\left[(2 \xi-1)\left(\bar{\theta}^{\prime}-\bar{\theta}\right)+\xi\left(\hat{\theta}_{p}-\hat{\theta}_{p}^{\prime}\right)\right]+\gamma x \xi\left(\hat{\theta}_{a}^{\prime}-\hat{\theta}_{p}^{\prime}\right)<0 .
\end{array}
$$

The first term into the two square brackets is negative since $\xi>1 / 2$. All the other terms are negative from Claim 1 and from $\hat{\theta}_{a}^{\prime}<\hat{\theta}_{p}^{\prime}$; hence the number of criminals to which immigrants are exposed reduces. The derivative:

$$
\frac{\partial\left(X_{i}^{\mathrm{ex} \prime}-X_{i}^{\mathrm{ex}}\right)}{\partial \gamma}=\xi\left(\hat{\theta}_{a}-\hat{\theta}_{a}^{\prime}-\hat{\theta}_{p}+\hat{\theta}_{p}^{\prime}\right)+x \xi\left(\hat{\theta}_{a}^{\prime}-\hat{\theta}_{p}^{\prime}\right)
$$

is negative since the first term is null (recall that $\hat{\theta}_{p}^{\prime}-\hat{\theta}_{a}^{\prime}=\hat{\theta}_{p}-\hat{\theta}_{a}$, as shown in 
the proof of Proposition 11 while the second term is negative because $\hat{\theta}_{a}^{\prime}<\hat{\theta}_{p}^{\prime}$. Hence, the reduction in the number of criminals to which immigrants are exposed is larger the higher the initial share of undocumented immigrants.

The change in crime to which natives are exposed amounts to:

$$
\begin{array}{r}
X_{n}^{\mathrm{ex} \prime}-X_{n}^{\mathrm{ex}}=\gamma\left[(2 \xi-1)\left(\bar{\theta}-\bar{\theta}^{\prime}\right)+(1-\xi)\left(\hat{\theta}_{a}-\hat{\theta}_{a}^{\prime}\right)\right] \\
+(1-\gamma+\phi)\left[(2 \xi-1)\left(\bar{\theta}-\bar{\theta}^{\prime}\right)+(1-\xi)\left(\hat{\theta}_{p}-\hat{\theta}_{p}^{\prime}\right)\right]+\gamma x(1-\xi)\left(\hat{\theta}_{a}^{\prime}-\hat{\theta}_{p}^{\prime}\right) .
\end{array}
$$

This expression is positive for $\xi=1$ since in this case $X_{n}^{\mathrm{ex} \prime}-X_{n}^{\mathrm{ex}}$ coincides with the change in the number of criminals targeting the natives (which is positive from what shown in Proposition 11. In the case, $\xi=1 / 2, X_{n}^{\mathrm{ex} \prime}-X_{n}^{\mathrm{ex}}$ reduces to:

$$
\frac{\gamma\left(\hat{\theta}_{a}-\hat{\theta}_{a}^{\prime}\right)}{2}+\frac{(1-\gamma+\phi)\left(\hat{\theta}_{p}-\hat{\theta}_{p}^{\prime}\right)}{2}+\frac{\gamma x\left(\hat{\theta}_{a}^{\prime}-\hat{\theta}_{p}^{\prime}\right)}{2}<0
$$

Hence, in this case the number of criminals to which natives are exposed diminishes after the amnesty.

\section{B Figures}



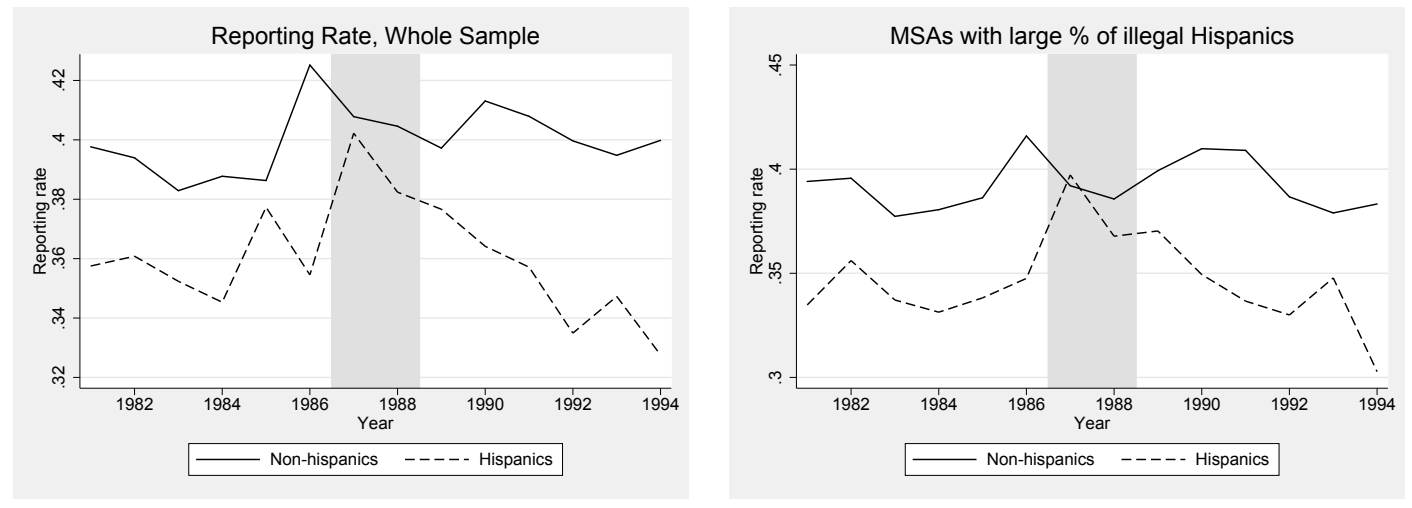

Figure 9: Reporting rates in all MSAs (left) and in those in top tercile by size of the Undocumented Hispanic population (right).

Notes: Based on NCVS data matched with the 1980 Census.
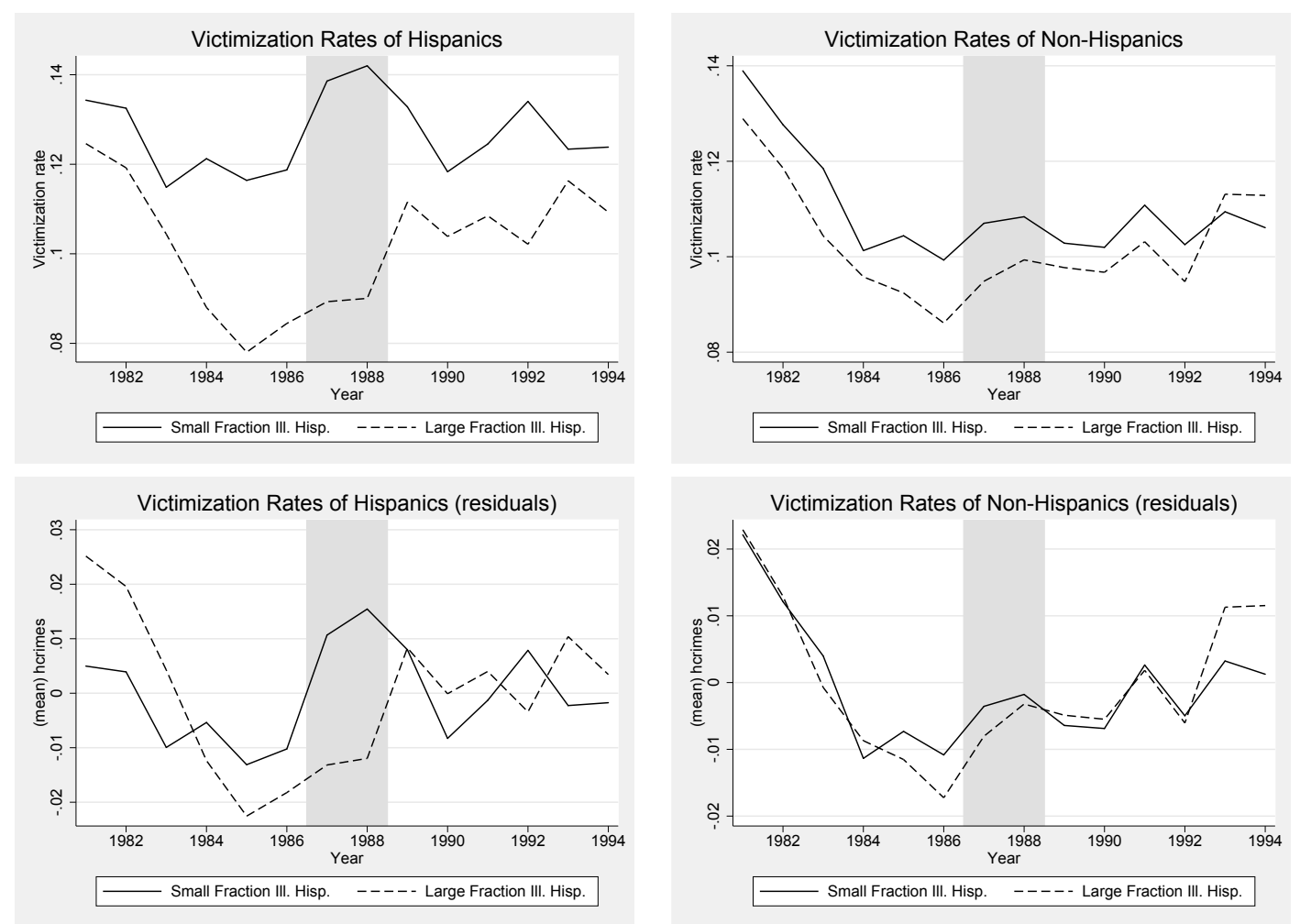

Figure 10: Reporting rates in MSAs with top tercile (top) and bottom two terciles (bottom) by size of the Legal or Illegal Hispanic population.

Notes: Based on NCVS data matched with the 1980 Census. 